\title{
Economic Growth in Gujarat in Relation to the Nation and Other States in Recent Times - A Statistical Analysis
}

\author{
Sebastian Morris
}

W.P. No. 2012-11-02

November 2012

The main objective of the working paper series of the IIMA is to help faculty members, research staff and doctoral students to speedily share their research findings with professional colleagues and test their research findings at the pre-publication stage. IIMA is committed to maintain academic freedom. The opinion(s), view(s) and conclusion(s) expressed in the working paper are those of the authors and not that of IIMA.

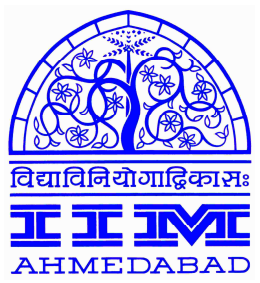




\title{
Economic Growth in Gujarat in Relation to the Nation and Other States in Recent Times - A Statistical Analysis
}

\author{
Sebastian Morris ${ }^{1}$
}

\begin{abstract}
Growth rates of regions (states) have generally followed the national level growth rates over time with small lags or leads. We find much coherence between the aggregate performance of regions over time and that of the nation, so that the periodization at the national level is also useful at the regional level. Growth of regions since the reform of 1991-93 can be considered in two phases 199294 to 2002-03 and 2003-04 onwards. The very growth achieved in the latter period is mirrored at the regional level with particularly the services sector growth rate moving upwards in the second period. Gujarat like many other states is no exception. But its large competitive advantage in manufacturing means that the growth achieved in the manufacturing sector may have been less than what was possible given the monetary and exchange rate conservatism of the Reserve Bank of India. Both Maharashtra and Gujarat in the period since 2003-04 show strong positive residual (regional) factors explaining their high growth performance in this period. The contrast is with Tamil Nadu and West Bengal in the very same period.
\end{abstract}

What is remarkable though of Gujarat is that it has been able to maintain and enhance its comparative advantage despite a high level of per capita income. Gujarat shows better performance on both agriculture and electricity but especially the latter which therefore inter alia has influenced local industrialization. But the roles of the factors considered must not be exaggerated. Coherence of national level growth with regional being high, the focus in discussions of the performance of states and state governments should shift to income distribution, performance of public services, locally provided infrastructure, social services over which state governments have far better and possibly even overriding control.

\section{Introduction}

Gujarat has been one of the fastest growing regions in recent times. Yet the mapping of its growth has not been clear enough. More than even the mapping, the immediate reasons that underlie the high growth of Gujarat (and several other states) need to be addressed. There has been a tendency among regional scholars to focus on the growth experience of regions (states in the Indian context) without significant reference to the major shifts in national level policies and growth at the national level which have deeply affected their growth. ${ }^{2}$ There is also much disagreement on the economic performance of Gujarat or on the reasons for the same (Bagchi et al, 2005, Dholakia, R. 2000), or of its significance to overall development (Hirway, 1995,2000 and Dholakia, 2007). While we have ourselves written about the same (Morris, 2006a,2006b), the present paper is concerned more about the relative performance of Gujarat vis-à-vis other states, and bringing out the core features in the regional experience ${ }^{3}$. The significant variations in growth experience have in many ways corresponded across states as we shall see. As the economy integrates and regional specialization

\footnotetext{
${ }^{1}$ Professor, Indian Institute of Management, Ahmedabad 380015. Email: morris@iimahd.ernet.in .

The author thanks Ms. Indira Hirway for support and encouragement.

${ }^{2}$ Dholakia, Ravindra $(2007,1994)$ are exceptions in this regard. While in an ex-post and accounting sense the growth of the nation is the weighted average of the growth of regions, regional growth is majorly influenced in the causal sense by the growth of other regions and national level macroeconomic policies are important in explaining the performance of any region over time.

${ }^{3}$ Dholakia, Ravindra (1994) does the analysis of various regions over the eighties. This paper may be seen as taking forth the analysis of regions since the reform up to 2010.
} 
increases, regions given their "endowments" are expected to grow differentially especially in terms of the rates of growth of broad sectors, and these need to be considered before specific regional policy is evoked to "explain" differences. In many ways national level policy reform such as the movement to value added tax from output taxes, increased connectivity and falling communication costs, or increased scope for international exchange and investments, all enhance the scope for significant interdependence and correlation among the growth of regions. Yet other important determinants such as the variation in the efficacy and efficiency of publicly provided infrastructure, and related goods and services (and where the responsibility lies with the regional governments), tax concessions at the regional level, working of the municipal and provincial governments - especially in how far they are investor friendly are regional factors that explain in part the differences in the performance of regions. Of course they would have to be posited against the significant medium term influence of "structural factors" such as those arising out of agglomeration economies. Similarly, vast internal labour movements, now in India, further negate the validity of pure region by region analysis. Reference to the interaction between regions and the national level policies and structural changes are therefore necessary for any satisfactory consideration of regional performance.

\section{Indian Growth Experience ${ }^{4}$}

Indian growth experience since the reform of 1991-92 can be considered in several phases. After a year of decline in 1991-92 and 1992-93, growth accelerated for reasons that are well known ${ }^{5}$. The textbook fashion in which stabilization was carried out (deep depreciation, monetary tightening, and large cuts on public expenditure) reduced expenditures and redirecting them to tradables goods production to allow the economy to reach a non-inflationary position of demand being well within the supply potential even though inflation could come down only with a lag. The major and coordinated structural initiatives that were simultaneously or quickly followed - freeing private investments, opening the economy to foreign investments both portfolio and direct, abolishing the Industrial Policy Resolution 1956, that had kept many important sectors reserved for the public sector, complete convertibility on the current account, unleashed the inherent and long suppressed potential of the economy to grow rapidly. It grew at rates than exceeded $6.5 \%$ on the back of exports that grew at nearly $20 \%$ p.a. in US\$ terms. For nearly four years after the reforms, belying the near consensus among economists then that Indian exports and the current a/c gap was unresponsive to currency values. Equally importantly private investments grew so rapidly that despite the fall in public investments, overall investments could growth could accelerate, so that the share of investment in GDP rose to nearly $29 \%$ of GDP, by the end of 1996-97. The structural reforms especially de-licensing, FDI openness, and privatization greatly improved the competitiveness as well as overall efficiency of investments. Additionally infrastructural performance improves in areas like telecom, ports and airlines. These meant that the potential output could outpace the demand increases due to export increase and investments to result in a non-inflationary high speed growth.

Rapid growth was arrested largely because the rupee was allowed to appreciate from 1995-96 in real effective terms, which slowed down exports with a lag starting from early 1997. Additionally the lack of clarity with regard to regulation and frameworks for private investments in most of the infrastructure sectors -roads, electricity, water, transport, municipal services, slowed down private investments from 1996 onwards, so that the impending recession could be predicted. (Morris, S., 1997). Indeed growth had slowed down well before the East Asian crisis, which then provided a bogey for policy makers. Monetary conservatism from $1997-98$ onwards, the high interest rates and the attempt to lower the fiscal deficit by cutting government expenditures, kept growth low at under

\footnotetext{
${ }^{4}$ Based on Morris, S. 2011, mimeo. India's Growth Experience in Recent Times. Presentation in various teaching sessions, IIMA.

${ }^{5}$ See Joshi and Little (1996) for an early macroeconomic study of the period till 1995-96.
} 
5.5\% from 1997-98 to 2003-03. (Morris, S., 2003). Reserve money growth in this period was no more than $13 \%$. Willy-nilly the money supply growth increased from 2004-05 onwards since the capital inflows which hitherto were largely sterilized, by reducing domestic credit could not so be done as the domestic credit level had turned negative! The high growth in money which had followed the vast increase in government expenditures, on account of the spending on the Golden Quadrilateral (finally the contract form and the policy for highway development the NHAl got right in 2002), the large autonomous increase in service exports, and the revival of the global economy pushed Indian growth to a high level of 9.5, with an average growth of 8.5\% over the period from2003-04 to 200708. Significantly well before the global crisis began, in response to the largely supply side inflation from 2006 onwards, the RBI began to tighten monetary expansion by raising the CRR repeatedly, and then allowing the rupee to appreciate even in nominal terms.

On the eve of the crisis growth had slowed down from a high of $9.5 \%$ to under $8.5 \%$ when measured on a quarterly basis. The RBIs response to the immediate dollar liquidity crisis was to first restrict dollar availability. Then when the Lehman Brothers' collapse took place resulting in large outflows of capital by all Flls. The RBI after some delay sold dollars, but without the concomitant reverse sterilization by expansion of domestic credit, to keep reserve money on the RBIs own target. As a result the dollar liquidity shortage was converted to rupee liquidity crisis and that braked the economy sharply! (Varma, J.R., 2009) It was only much later that the central bank in view of the global liquidity could be persuaded to expand liquidity reluctantly, which when carried out resulted in a bounce back, which was sustained on the back of a fiscal boost provided by the central government, which had just been reelected, amounting to some US\$50 billion. This boost although not compositionally the optimal, allowed for the quick rise in public spending of growth to restore growth to $8.5 \%$. The composition of the stimulus could have been much better had the share of investment in the same been higher. While there was a significant component of infrastructural spending both urban and rural, not only were these expended at lower levels of efficiency than earlier, but the component of consumption was large, since the increased outlays on the National Rural Employment Guarantee Scheme (NREGS) was a significant part of the stimulus. The tax deduction component was not particularly consumption oriented since the private savings rate did not fall in this period.

In less than a year and a half after the stimulus, under the general demands from policy commentators and the central bank to exit the stimulus, the tax concessions, both direct and indirect were withdrawn first, then government expenditures fell. These combined with the RBIs monetary tightening on account of high inflation resulted in a steady deceleration of growth and especially of investment which now fell to less than 3\% growth after having reached a record $19.5 \%$ at the peak during the high growth phase. Growth itself would fall to less than $5 \%$ in the second quarter of 2012-13. The inflation being on the supply side due to limitations in the growth of agricultural side (on the high demand unleashed by inter alia the NREGS and the high growth period which was also poverty reducing) to quickly respond, and to a resurgence of commodity prices did not count for much in the RBIs thinking. In effect then over the last year a situation of inflation has been converted to a situation of stagflation and the RBls stance has been that the continuing fiscal deficit gives it little room for action.

Here we are less interested in a critique of the policy stances of either the central government or the central bank, but in delineating the growth phases that the Indian economy has seen in recent times. We may discern several distinct periods since the Economic Reform. 


\section{The Regional Experience}

The growth experience of the major states especially those industrially oriented, and those that house important portions of the tradable services sector would show a broad concurrence with the trends drawn above of the national economy. Since there is no regional data on output other than the State Domestic Product (SDP), and the latest available figures of this data set do not go any further than 2010, only the first three periods of Table 1 can be meaningfully considered. On a larger time span, the SDP figures for most of the states are not available prior to 1970-71. Therefore of the Plan Periods (1950-1964) including the Mahalanobis Period (1956-1964), the "Hindu-period" (19651979), and the revival period (1980-1992), only the latter fully and the "Hindu-period" in part can be considered.

In using SDP we have carried out the analysis considering two sets of periods. (1) Before 1979 (2) 1979 onwards for certain kinds of questions; and (1) before 1979 (2) 1979-80 to 1992-93 (3) 1993$94-2002-03$ and (4) after 2004 for certain other questions. It is important that the periods chosen for the analysis of the regions correspond in more ways than otherwise with the overall national experience and the key turning points in the economy as a whole.

Thus 1964 marks the failure of the Plan and the period since then right until 1979 is marked by failed attempts to get back to the Plan and to use government controls to direct the economy. From 1964 onwards the "Hindu-period" happened, wherein the government turned sharply re-distributive and 1979 marks the end of the period. Some states (Gujarat for example) show 1975 instead of 1979 as the start of the revival of the eighties but these are exceptional. Similarly the slowdown of 199798 marks the shift to fiscal and monetary conservatism, and 2003-04 to fiscal exuberance but continuing monetary conservatism in stance but realized expansion for a while. Thus it is important to go beyond the periods covered by the various SDP series (with different base years) to periods derived from the national growth experience. This necessarily involves chaining the various SDP series. Since the net state domestic product at factor cost (NSDP) at 2004-05 prices was the series available for the largest number of states and for periods, we have used the same and chained other NSDP series backwards. In chaining the data, the newest base year series was accepted for the years with overlap, and the previous series was used to extend backwards with the average of the earliest (with reference to the latest base year series) two years of overlap was used to arrive at the chain factor. The geometric average of the ratios was used to back project the latest base year series to take the data all the way back to 1961 or 1971 depending upon the coverage of the earliest series available.

States like UP, Bihar, MP, Jharkhand, Chhattisgarh, Uttarakhand posed particular problems of compatibility across time owing to the division of the states ${ }^{6}$. For Jharkhand, Chhattisgarh and Uttarakhand the data as such was used. For MP, Bihar, and UP the current data covering these states in their current geographical areas was used and pushed backwards using the growth rate of the larger "integrated entity" would have had, for the region now covered by these states. Lacking district level data this was the only option. ${ }^{7}$ Unlike the usual practice of keeping aside the smaller states, we have included them. In statistical analyses besides the requirement of sufficient data points, missing out on an entire category or categories would render the conclusions from regressions etc. less general than otherwise.

\footnotetext{
${ }^{7}$ It is justified in statistical studies of all regions, that seek to establish growth rates or even relate growth rates to other factor as long as these factors are also so derived.
} 


\section{The Growth Experience of Various States}

One way of summarizing the growth experience of various states would be to report the growth experience of the nation since that is the output (or the production value added) weighted for size. This would involve a national level analysis. At the national level there are several available time series including those of national income, and the same have been widely analysed.

We in this paper also seek the growth experience which is not so weighted, but where each region gets a equal weight. This we have carried out by regressing the growth rate of GDP of states over time dummies and then taking the fitted values. While all time dummies are not significant, the overall significance of the regression (overall $\mathrm{P}$ and $\mathrm{F}$ values) give validity to the approach. The fitted values give the movement of NSDP over time that most states went through, and is conservatively estimated from 0 or the overall average across periods. We use $\ln \left(Y_{t} / Y_{t-1}\right)$ as the symmetric growth rates rather than the usual $\left(Y_{t}-Y_{t-1}\right) / Y_{t-1}$, since the latter being asymmetric can give spurious period average growth rates especially when the volatility is high. In other words the usual measure is not invariant with respect to time reversal. Thus if $\tilde{Y}_{t}^{i}=\ln \left(Y_{t}^{i} / Y_{t-1}^{i}\right)$ (defn.) then

$$
\hat{\tilde{Y}}_{t}^{i}=\theta+\hat{\beta} \cdot D_{t}+\varepsilon_{t}^{i}
$$

where $D_{t}$ is a vector of time dummies, and $\tilde{Y}_{t}^{i}$ is the growth rate in the NSDP of the region $i$ at time $t$ set up as a panel. These growth rates are expected to be lower in absolute values than the growth rates of the nation as a whole, but are truly representative of the changes valid for the periodization of the regions as a whole. Table 2 reports the estimated value of equation (1) along with the growth rates of the nation as a whole. Overall NSDP at factor cost at 2004-05 prices and chained to earlier series as mentioned before is considered, for the three broad sectors. See Fig. 1 for a plot of the growth rates of the nation in the sense above as estimated by coefficients of the time dummies.

The link with national level performance can be more directly established through a regression of regional growth rates on the national level growth rates.

Consider :

$\tilde{Y}_{t}^{i}=\theta+\hat{\beta}_{0} \cdot \tilde{Z}_{t}+\hat{\beta}_{1} \cdot \tilde{Z}_{t} \cdot D_{1979-1992}+\hat{\beta}_{2} \cdot \tilde{Z}_{t} \cdot D_{1993-2002}+\hat{\beta}_{3} \cdot \tilde{Z}_{t} \cdot D_{>2002}+\varepsilon_{t}^{i}$

where $\tilde{Z}_{t}$ is the growth rate at the national level. Significance of $\hat{\beta}_{0}$ establishes the dependence on national level factors and the co-movement so that there is strong expectation of the same periodization of the economy at the national level to hold at the regional level on the whole. Other coefficients check for any significant difference in the elasticity of growth at the regional level to the national. Observe from Table 3 that $\hat{\beta}_{0}$ being estimated to be 0.95 that is very nearly 1 . During the period immediately following the reform i.e. 1993-2003 this had come down as indicated by the coefficient of the interaction dummy for the period being significant and less than 0 . This implies that the period 1993-2003 was one of major structural change and realignment in terms of the spatial location would have taken place during this period. Below we establish more directly the periodization at the regional level. 


\section{Structural Breaks and Periodization}

While at the national level it is indeed true that the economy shows the periods as in Table 1, for the states it is important to establish that the same structural breaks would be valid. Given the limitations of the state level data (much of it does not include comprehensively the earlier Plan Periods from 1956-1964) and the understanding that the two most important structural breaks are at 1979 (after which the economy grew rapidly at 5.5\% from the earlier "Hindu" growth rate of 3.5\% from 1964 onwards), and then the structural adjustment /stablisation of 1991-92, we check using a dummy variable analysis to show the significance of the choice of the same for further analysis using state level data. While for some states it is possible to check for the earlier structural break, we have not done so but assumed the same given all the analysis with state and national level data that has already been done and instead check whether the period from 1992 onwards (i.e. the reform period constitutes a major departure from the earlier period considered together ${ }^{8}$.

We carry out each of the regressions below:

$$
\ln \left(Y_{t}\right)=\hat{\alpha}_{0}+\hat{\beta}_{0} \cdot t+\hat{\alpha}_{1} \cdot D_{>1992}+\hat{\beta}_{1} \cdot t \cdot D_{>1992}+\varepsilon_{t}(\text { for each state) } \ldots \ldots . .(3)
$$

The constant and the slope are both separately examined for change with respect to the period dummy $D_{>1992}$ with $\ln \left(Y_{t}\right)$ being variously the estimate of NSDP in major sectors (for each year for a state). The regressions are carried out separately for each state and the results summarized in Tables 4, 5, 6 and 7. For the states Chandigarh, Chhattisgarh, Jharkhand, Manipur, Mizoram, Sikkim, and Uttarakhand there was not sufficient data over the two periods to meaningfully carry out the analysis. Significance of change would be the t-values being greater than 2 for $95 \%$ significance, and the coefficients (and constant) of the time dummy being larger/less than zero. We are not particularly interested in the level difference here since the question is one of a change in growth rates.

\section{NSDP (all sectors) at Factor Cost at 2004-05 Prices}

Observe that in all states except Andaman and Nicobar Islands, Arunachal Pradesh, Goa, Punjab, Uttar Pradesh and Assam there has been an improvement in growth rates so that the one single factor for the improved performance of all states since 1992-93 has been the economic reform of the Narashima Rao government which in many ways transformed the basis of the economy and the orientation of policy being more than a "regime shift". For the nation as a whole the dummy variable regression gives very high significance to the structural break from 1992-93. The states with the most change in their growth rates of over 3\% over the reform period are Andhra Pradesh, Gujarat, Himachal Pradesh, Karnataka, and Kerala. Kerala increased its growth rate since the reform by a whopping $9 \%$ over the realized growth rate of $-3 \%$ in the pre-reform period. Since the data for the states span different time periods detailed cross state comparisons are not very meaningful. For Gujarat there was a significant improvement of $3.37 \%$ over 3.37 achieved in the earlier period so that reform made a major difference as in many other states. The improvement was between 3 and $1.5 \%$ in the case of Bihar, Delhi, Haryana, Jammu and Kashmir, Maharashtra, Madhya Pradesh, Nagaland, Orissa, Puducherry, Tamil Nadu, Tripura and West Bengal.

\section{NSDP (Agriculture) at Factor Cost at 2004-05 Prices}

\footnotetext{
${ }^{8}$ We preferred the approach of dummy time periods over that of the chow -test in order to be able to distinguish between change in growth rates and a level shift over the period. (See Gujarati, Damodar (1995)). Log of values have to be necessarily used since with constant growth rates the log of GDP is expected to be a straight line over time.
} 
In the case of agriculture though there is no significant change in the growth rates since the reform for the country as a whole. "Significant" change is only observed in some of the smaller states Andaman, Arunachal Pradesh, Assam, Delhi (all declining)), besides sharp and significant declines in Punjab and Haryana (which are losing their comparative advantage in agriculture due to high wage costs) and West Bengal (where very high growth rates were registered in the first period since the launch of Operation Barga in 1982-83 ). Significant improvement is shown only in Bihar, Puducherry, Tripura, AP, and a lower level of significance (less than 95\%) in Gujarat. Thus the central governments reforms were not the overwhelming aspect in the performance of regions since 199293 so that state level explanations in this case are very important. Later when we look at the changing comparative advantage of states in agriculture, we shall see that besides the state level factors, collective performance and performance in other sectors would have affected agricultural performance.

\section{NSDP (Manufacturing) at Factor Cost at 2004-05 Prices}

In the case of manufacturing the nation as a whole shows a significant change in the growth rates during the post stabilization/ structural adjustment in relation to the past period. ${ }^{9}$ Yet not many states show a significant improvement in the growth rates in the second period. The level effects are of course generally positive as witnessed by the dummy level values being positive and significant. Part of the difference is of course due to the fact that most states have a 40 year time data whereas for the country as a whole the data is for 50 years, and included two years of high growth towards the end $(2008-09,2009-10)^{10}$. Partly it is also because regional manufacturing (and output) would fluctuate more than the national level manufacturing and output (Robinson, E.A.G, 1957). Nevertheless the difference is real. Thus in so far as manufacturing is concerned, we would suggest that the reform period saw a realignment of the shares of states and more so a significant broad based improvement in the growth rates that encompassed many states. Notable increase in growth rates have taken place in Orissa, Puducherry, West Bengal, Kerala, and Rajasthan. Bihar, Delhi, Haryana, Punjab Karnataka,, Madhya Pradesh, and Uttar Pradesh the rates have declined. In the richer states of Punjab, Delhi and Haryana this is only to be expected but the decline in the other major states is on account of adverse regional factors. In most of the other major states there was no notable change in the manufacturing growth rates. See Table 6.

\section{NSDP (Tertiary Sector) at Factor Cost at 2004-05 Prices}

In the services sector the is picture is radically different. Not only in the nation as the whole, but in all states except A\&N, Arunachal Pradesh, Assam, Goa, Meghalaya, there was significant step up in the growth rates from $0.7 \%$ (Rajasthan) to $12.37 \%$ (Kerala) showing the highest step up in the growth rate. Besides Kerala, Andhra Pradesh, Delhi, Gujarat, Himachal, Harayana, Maharashtra, Orissa, Puducherry, Tamil Nadu and West Bengal show step up in their growth rate above $2 \%$.

\footnotetext{
${ }^{9}$ Seemingly this finding is seemingly in contrast to that found by Nagarai (2000) that the reform did not improve growth rates in manufacturing. But the periods considered are different. Moreover it is important to realize that Nagaraj's findings are in relation to the 80 s when growth was high though unsustainable. Here we are looking at the post stabilization/ structural adjustment period in relation to the entire period before the same. While the 80 s constitute a distinct period, the data at the state level was not generally sufficient to draw out the differences between each of the three periods. Moreover the growth in the $80 \mathrm{~s}$ being unsustainable (rising inflation, besides c/a and fiscal deficits), and 1991-92 1992-93 constituting a distinctly different regime of liberal trade and investment regime there is meaning in the choice of the period.

${ }^{10}$ The slowing down over 2012-13, which is expected to continue for a while should change the overall average post 2003 quite a bit.
} 
Tradeable services which is known to have grown very rapidly since the reform and reached significant size in India's current account earnings, besides the rapid rise of trade and financial services underlie the observations. Thus the distinct improvement in the NSDP since the reform is to a large extent on account of the improvement in services sector, which has been broad based. See Table 7.

Similar analyses could have been carried out for the narrower sectors in the NSDP such as construction, trade hotels and restaurants, but our main purpose was to establish the periodization, the broad features in the performance since the reform.

\section{Three Broad Periods}

In an aggregate sense ${ }^{11}$ it is possible to establish three distinct periods (prior to 1979, 1979 to 1992 (the period of revival and partial reform), and from 1993 onwards (the reform period). To do so for the states as whole, we took the cross sectional (an average for each state) of the growth rates in NSDP at factor cost and its components. We regressed the same on three period dummies, and forcing the model to pass through origin (which is equivalent to the constant being estimated by the coefficient of the first period dummy). So the coefficients of each of the period dummies give us an estimate of the average growth rates achieved in each of the periods, and the t-values tell us whether these are significantly different. The regression model is:

$$
\frac{\sum_{t} \tilde{Y}_{t}^{i}}{n^{i}}=\hat{\beta}_{<1979} \cdot D_{<1979}+\hat{\beta}_{1979-1992} \cdot D_{1979-1992}+\hat{\beta}_{1 \geq 1993} \cdot D_{\geq 1993}+\varepsilon^{i}
$$

$n^{i}$ is the number of years of the period over which the growth rates of various states were available. The estimates of the various $\hat{\beta}$ along with the t-values are reported in Table 8.

Observe that for NSDP there has been a distinct improvement in the third (reform) period, with little difference in the estimate across states between the two earlier periods. Thus we can conclude that in the second period the rise in GDP of the nation above the rate achieved in the period prior to 1979 was not as broad based as in the third period. The period before 1979 is also affected by the somewhat higher growth achieved in the Plan Period (1956-79) in the states for which data go as far back as 1964. But the enhancement of the growth rate since the reform, and the broad basis of the same is beyond doubt. The low values of $R$ and $R^{-}$sq. are only to be expected since we have already averaged the growth rates across the years that constitute the period.

With regard to manufacturing there is a distinct fall so that we cannot conclude that manufacturing got a big boost with the reform. Nagaraj, R. (2000) working with national level data had pointed out this feature of the reform and Morris, S. (1997) and Morris, S. (2003) had brought out the biases against manufacturing in the policies at the national level - exchange rate being not sufficiently aggressive, monetary conservatism and high energy costs against manufacturing, the "dutch disease" effect of remittances and large service exports (Morris2005) despite the removal of other major distortions against manufacturing in the form of high taxes, and high import duties, and controls restrictions and reservations that characterized the pre-reform period. The decline in

\footnotetext{
${ }^{11}$ Herein we assume that there is meaning to realized average growth rates for each of the states across a period for each of the periods, i.e., they are what are real instead of the engine generating the same. This can at best be an ex-post justification for the periods. (The states are then considered as realizations from an archetypical state)
} 
registered manufacturing is to be particularly noted. There is no compensating pick up of unregistered manufacturing much of which is informal, either.

Agriculture per se and the primary sector (which includes forestry, fishing and mining) too shows such a decline, though in the case of agriculture proper given the large volatility the difference is just about significant.

Banking, insurance etc, and public and social service, shows a similar decline, but with very high rates still continuing. All other subsectors of the tertiary sector show increases, including the tertiary sector as a whole. Thus in the sense of encompassing most regions it is the expansion of the services sector that constitute the major realized "effect" of the reform. The increases in the growth rates of construction, hotels and restaurants, and real estate are to be particularly noted and they fit the pattern of spending led, with the spending of the incomes realized from the tradable services sector.

\section{Convergence in Growth Rates}

Within an economy there are strong forces to allow one to validly expect that per capita incomes would not diverge across regions without limits. The reasons for the same are inter regional movement of both factors capital and labour (while land cannot move), and internal transfer payments as when urban workers and migrant labour send home money to their families, and due to terms of trade shifts -as when agricultural goods prices rise relative to industrial, to shift incomes to agriculturally oriented regions. These processes given no exchange rate risk, tariff and visa barriers, or "country risk" would be far more vigorous than internationally so that regional income inequality when measured by the disposable income is not likely to very large. High growth through would tend to pull out these variations since growth of industries have an agglomeration aspect, but the counteracting forces already mentioned would also begin. Nevertheless the inequality in terms of production per capita could be significantly larger though still bounded by the very same forces except that transfer payments. There have been various views on the high growth during the reform, including one that the divergence of incomes between states has increased. The above is only to be expected at least in the short to medium term and when measured by production rather than disposable income since even equal growth from different per capita incomes would ensure that result.

It is more meaningful to ask if growth rates have shown a tendency to converge, i.e. if the growth rates in a period have depended inversely on the per capita income in a prior period. If indeed so then growth processes in the country in a spatial sense would not fracture the economy but would instead integrate the same. The analysis should ideally have been conducted on disposable incomes at the state level, but since such data is not available, because that would require measures of interregional transfers both public and private besides state level production data (NSDP), the analysis is carried out using NSDP. If convergence is observed in an analysis with such data then convergence using disposable income is only to be expected, since transfers due to inter-regional remittances by workers are expected to dominate over transfers out of profit income, and the former would be from the higher growth and high income areas to the lower growth and lower income areas.

Therefore the analysis regresses the growth rate in NSDP (or its components) on the per capita NSDP in a a year prior to the period (the periods being a priori defined). In order to simultaneously ask the question of relative convergence across periods we have constructed the following model. 


$$
\begin{aligned}
& \tilde{Y}_{t}^{i}=\hat{\alpha}+\hat{\beta} \cdot y_{\text {prior_to_ } \text { period }}^{i}+\hat{\beta}_{1979-92} \cdot y_{1978-79}^{i} \cdot D_{1979-92}+\hat{\beta}_{1993-2003} \cdot y_{2002-03}^{i} \cdot D_{1993-2003} \\
& +\hat{\beta}_{2003+} \cdot y_{2002-03}^{i} \cdot D_{2003+}+\varepsilon_{t}^{i}
\end{aligned}
$$

$y_{1978-79}^{i}$ for example is the per capita NSDP in a year just prior to the period (1979-92). Thus for a state for the years between 1979-80 and 1992-93 it is the per capita income of the state in the year 1978-79. Convergence since 1960-61 (the earliest year for which the NSDP is available) is observed if the sum of the $\hat{\beta} \mathrm{s}$ is negative and the overall significance of the regression is established. If say $\hat{\beta}_{1993-2003}$ is significantly negative then it means convergence has been higher in the period from 1993-94 to 2002-03 than over the period before 1978-79.

In this regression we have also considered the period from 2003-04 onwards separately, although there were few (but adequate) data points. The reference period is therefore the pre-partial reform period which we may consider as the period of controls and planning, and state based development. The results are reported in Table 9.

Observe that convergence is observed for NSDP and for all the major sectors separately with reference to the prior period NSDP (sum of all the coefficients is negative). Therefore there is no basis for the thesis that the growth in India has been regionally fractured, despite significant divergence of income per head. What we mean is that growth is self-correcting since the rate of growth is sensitive to the prior period per capita NSDP being ceterius paribus lower when the prior period per capita NSDP is higher relatively. Recognizing the vast barriers to factor price equalization that still exist in the economy (barriers to movement of people coming from administered access to land in cities, infrastructural problems that limit the trade within the economy across time and space, and policy constraints on movement of goods and services - largely in agriculture but also in goods and services (through the existence of state level differential taxes)) this observed convergence would mean that ensuring rapid growth is the most important aspect of any solution to the problem of regional inequality (besides of course fiscal transfers). Yet the convergence is of a small order - the maximum for the period as whole $-0.038 \%$ in growth rates of the tertiary sector, and the best for any period and any sector is for tertiary sector in the immediate post reform period 1993-94 to 2002-03. The impact of a 10\% rise in the prior period NSDP the impacts are just about 1.5 to $11 \%$ improvement in the growth rate. The convergence is better for the tertiary sector (the significance is also higher), and for both agriculture and $\mathrm{mfg}$ it is weak. The main conclusion is that there is no thesis that growth has been divergent in the Indian economy for any period and certainly not for any of the post reform periods, which have shown distinctly stronger convergence. In this analysis the reference has been the per capita NSDP, irrespective of the sector of which the growth rate is under consideration

In a further confirmatory analysis we regress the average of the growth rates in a period on the prior period average per capita NSDP as well as the per capita NSDP in the sector under consideration.

The model is as follows:

$$
\begin{aligned}
& \tilde{Y}_{p}^{i}=\frac{\sum_{t} \tilde{Y}_{t}^{i}}{n^{i}}=\hat{\alpha}+\hat{\beta} \cdot y_{\text {prior } \text { period }, N S D P^{i}}+\hat{\beta}_{1979-92} \cdot y_{1978-79}^{i} \cdot D_{1979-92} \\
& +\hat{\beta}_{1993-2010} \cdot y_{1992-93}^{i} \cdot D_{1993-2010}+\varepsilon_{t}^{i}
\end{aligned}
$$


for NSDP and for each of the major sectors of the NSDP and $y_{1978-79}^{i}$ is variously the per capita NSDP in the sector in the year just prior to the period. In one set of regression (1) the second term is not used and in another (2) the second term is used when the dependent variable is for a sector of the NSDP.

Table 10 presents the results. Again observe that there is convergence of NSDP with respect to per capita NSDP for the period as whole and the convergence is larger in the from 1979 to 1992 but has weakened somewhat in the third period (post reform i.e from 1992-93 onwards).

For manufacturing there is little or no convergence. When per capita NSDP is also added, then there is a barely perceptible improvement in the convergence. In agriculture there is significant convergence and there are no significant differences from one period to another. Including per capita NSDP improves the model greatly pointing to agricultural comparative advantage (as we shall see later) being strongly dependent (negatively) upon the per capita income (which is an effective proxy for the wage costs in the industry). With the reform, the convergence in the manufacturing sector seems to have improved marginally but significance is at lower than $95 \%$. These results are not surprising. Manufacturing in a period of transformation would specialize into various locations with agglomeration economies and access to ports driving the process. Indeed this is the process that gathered much of industrial production into the coastal areas including around the Great Lakes in the US, and a similar process is on at a furious pace in China today which is unambiguously making its economic transformation. But the existence of convergence of SDP points to spatial equilibrating process through the operation of comparative advantage.

In the tertiary sector the convergence was strong over the period 1993-94 to 2002-03 relative to the others, and on the whole the convergence is statistically robust as well.

Thus the overall conclusion is that growth has not been a process that has been divergent in India, although the process of regional specialization is on. In terms of disposable income per capita we could not carry out the formal analysis though it is very likely that in this case the processes would have been significantly more convergent with the convergence rising in the period of 1993-94 to 2002-03, and marginally declining thereafter.

\section{States and Their Comparative Advantage in Agriculture}

In a rapidly growing economy there are changes as when sectors of the economy grow differentially. And the agglomeration economies would drive for a while differential regional growth as well. The agricultural sector unlike many others is an important sector and somewhat different from other sectors in being land dependent. Moreover the share of agriculture despite growth in a closed economy would decline as overall growth of the economy takes place. The reason is ofcourse that the share of food as well as of farm originating inputs comes down in overall final consumption. In an open economy with agricultural trade, when the growth of the economy is greater than the average for the rest of the world, the process is to some extent muted as when the country in question is land abundant relative to the rest of the world, and would be somewhat accelerated when the country in question is land scarce relative the rest of the economy. But because agricultural trade has significant monopoly and monopsony aspects, and global optimization of agriculture requiring the movement of people (since land is immobile), the agricultural sector can hardly be said to "free-trade" and optimizing global agricultural production. (See Morris, S.,2007). Within a country though, with free movement of labour, the agricultural economy under a liberal regime (free movement of people, free movement of goods including agricultural goods, and of capital), the law of comparative advantage would hold. 
Therefore land abundant areas, and low labour cost areas would have an advantage which would be reflected in their higher share of agriculture in the regional output. Land abundance would of course have to be modified by the endowments of rainfall which over fairly long periods would vary over an average that can be assumed to be constant unless there is major shift in the climate over the period under consideration. Higher land endowment per unit of population, and lower per capita income (lower labour costs) would increase the share of agriculture of a region. Such a determination of comparative advantage has its own uses since irrigation is in part determined by investments which are endogenous to the process. However If irrigation endowments are instead considered as being in part driven by exogenous factors (including terrain type, endowments of rivers and rainfall, besides public policy and action at the national level) there are reasons to consider irrigation as a given factor not easily changed by actions at the regional level in determining comparative advantage. We carry out the analysis from both perspectives to determine if there are factors other than these (unexplained factors) which can be attributed to "state level policies" and other idiosyncratic aspects, which have influenced the revealed comparative advantage.

Comparative advantage in the regional context could have been measured by the share of agriculture in NSDP in a particular state divided by the share of agriculture in the nation as a whole. Since the share of agriculture in the nation as a whole can be expected to decline with income growth and in a growing economy has a trend towards a fall, and is also influenced by national level policies, we have used the simpler share of agriculture in NSDP without normalizing the same with the share of agriculture for the nation as a whole because the same for any year is the same for all states so that in cross sectional analysis the normalization is not required, if other determining variables like per capita income are included. We carry out panel analysis and retain the simpler form to allow for income to affect the share, rather than a time trend. This allows the possibility for even a short period increase in the share even for the nation as whole (weighted average of the share of all the states) in a period of negative growth or in a period when there is reform /structural adjustment.

Thus

$$
A_{t}^{i}=\frac{Y a_{t}^{i}}{Y_{t}^{i}}=\hat{\alpha}+\hat{\beta}_{1} \cdot \text { PopDensity } y_{t}^{i}+\hat{\beta}_{2} \cdot \ln \left(y_{t}^{i}\right)+\hat{\beta}_{3} \cdot \text { Rain }_{t}^{i}+\varepsilon_{t}^{i}
$$

Where $A_{t}^{i}$ is the share of agriculture in NSDP of the $i^{\text {th }}$ state in the year. $Y a_{t}^{i}$ is the agricultural NSDP. PopDensity ${ }_{t}^{i}$ is the population density of the state measured as the population divided by the reporting area. $\operatorname{Rain}_{t}^{i}$ is the first component of the log of the Rainfall to the Normal Rainfall in the year and the previous year of a principal component analysis. For a (large) state with many "rainfall regions" as reported by the Meteorological Office, the average of the various regions is taken some rainfall regions apply to more than state (typically small in area states).

Table 11 reports the results of the regression above. This is our first model where irrigation has been kept out. Observe that there is a good fit to the parsimonious 2 factor model of population density and per capita income and with rainfall with the expected signs with high degrees of significance. Thus the basic determinants of comparative advantage are established. That the fit is acceptable is also given by the unbiased distribution of $\varepsilon_{t}^{i}$ around the fitted line. See Fig. 2 . The above model is extended with regional dummies for some states (Gujarat and its peers) and we observe from Table 12 that the dummy for Gujarat is not significant. This means that the revealed comparative advantage of Gujarat is about the same as that of other states (other than those with dummies). Andhra has a higher revealed comparative advantage than the model predicts alluding to positive 
regional factors at the state level. West Bengal is similarly placed as Gujarat. Both Tamil Nadu and Maharashtra which are similar to Gujarat in being leaders in manufacturing, with Gujarat leading the set, have negative values for dummies. Relative to them it is interesting and quite conceivable that Gujarat has higher comparative advantage in agriculture conditional on "structural or allometric" factors.

Fig. 3 and Fig. 4 plots the ratio of the observed share of agriculture to the fitted share of agriculture for both the manufacturing oriented states and some other states. While the higher ratio for states like Haryana and Punjab among those rich can be identified as arising out of the factors not considered in the model or in the poorer states like UP and WB due to lower wages, that of Gujarat relative to its manufacturing peers (TN, Maharashtra and Karnataka), being conditionally larger implies that there have been regional policies /actions - such as irrigation and other conducive factors that have kept up its comparative advantage. When we consider the model with irrigation (see tables $\mathrm{A} 12$ and $\mathrm{A} 13$ for the results without and with dummies), West Bengal, TN and Maharashtra its manufacturing peers show lower comparative advantage. Thus regional factors other than irrigation may as well have, relative to Maharashtra, TN and West Bengal contributed to the determination of comparative advantage and these have been positive for Gujarat relative to these three states. The same can be said about Karnataka as well.

The extended model with irrigation related variables (whose results are reported in tables A12 and A13) is as follows:

$$
\begin{aligned}
& A_{t}^{i}=\frac{Y a_{t}^{i}}{Y_{t}^{i}}=\hat{\alpha}+\hat{\beta}_{1} \cdot \text { PopDensity }_{t}^{i}+\hat{\beta}_{2} \cdot \ln \left(y_{t}^{i}\right)+\hat{\beta}_{3} \cdot \text { Rain }_{t}^{i}+\hat{\beta}_{4} \cdot I_{t}^{i} \\
& +\hat{\beta}_{5} \cdot \text { Iwell }_{t}^{i}+\hat{\beta}_{6} \cdot \text { Icanal }_{t}^{i}+\varepsilon_{t}^{i}
\end{aligned}
$$

$I_{t}^{i}$ is the Irrigation Intensity measures by the net irrigated area by the reporting area. Iwell $_{t}^{i}$ is the share of wells in the irrigated areas and Icanal $_{t}^{i}$ that of canals.

Observe that in this extended model the coefficients of the main determinants viz the population density and per capita income do not change much, pointing to the robustness of the "structural/allometric" model. Rainfall now becomes insignificant because the Irrigation related variables are able to encompass the same. Irrigation is measured in terms of area irrigated in a particular year and hence the variations therein are correlated to the rainfall in a particular year. Irrigation related variables work better than rainfall since average irrigation levels reflect enhancement of land endowments while their variation over time reflect rainfall variations. Observe that the coefficient for wells is negative which is reflective of the relative "ineffectiveness" of well based irrigation in relation to that of other sources of irrigation including canals.

In estimating the same model with dummies, again observe that the peers of Gujarat (Maharashtra, TN, West Bengal) have significantly lower revealed comparative advantage (agriculture shares) than Gujarat. Therefore we can strongly conclude that due to factors that go beyond irrigation per se Gujarat has been able to hold its comparative advantage in agriculture beyond those of its peer states. The reasons are possibly many including pricing of water, availability of electricity, transport infrastructure etc, but unfortunately it we could not formally establish the role of these except to a limited extent. See the discussion later on growth factors.

Thus when we regress the residuals of equation 7 on Irrigation related variables for a limited set of states which consist of the larger states including Gujarat's peers and others with high comparative advantage in agriculture with dummies as well for Gujarat and its peers, we observe that now the fit 
is better since the noise from the smaller states (with higher probability of idiosyncratic factors) is not there. Gujarat relative to its peers has a significantly higher comparative advantage, with West Bengal (a much poorer state being closer but still lower than Gujarat). See Table 15. Since the fit has improved for the limited set it is clear that the effect of irrigation intensity which is the most important determinant has somehow worked better in Gujarat. We would suggest that the systems are better managed and the better availability of power that would have improved the efficacy of irrigation may have been operative.

\section{Decomposition of Regional Growth into "Structural" and Residual Components}

If we assume that there are large agglomeration and national level demand factors that embed the growth of an industry in a region to the growth of the industry at the national level, then we may call this effect as arising from the past and the national level factors over which the region in question has little control. These we may call the "structural factor". This can be estimated as the growth that would have resulted had each industry in a region (as existing in the base year) grown at the national level industry average for that industry. Subtracting this structural growth from the actual realized growth, we may estimate the "residual effect" which is the effect of both regional factors (governance, availability of infrastructure, costs, local demands, etc). We have used each of the NSDP items (Agriculture, Forestry, Fishing, Mining, Registered Mfg, Unregistered Mfg, Construction, Electricity Gas and Water, Trade Hotels and Restaurants, Transport Storage and Communication, Real Estate etc, Banking Insurance etc, Public Services, Other Services), as a distinct industry; and therefore the "structural component" $S F^{i}$ is reflective of the broad changes in a region / across the economy. For each region we have worked out the two components.

$$
\begin{aligned}
& S F_{p}^{i}=Y_{j, p-\tau}^{i} \cdot\left(\frac{\frac{Y_{j, p}}{Y_{j, p-\tau}}}{Y_{p-\tau}^{i}}\right) \quad \text { and thesidual Component" } \\
& R F_{p}^{i}=T F_{p}^{i}-S F^{i}=\left(Y_{p}^{i}-Y_{p-\tau}^{i}\right)-S F^{i} \ldots \ldots \ldots \ldots \ldots \ldots . . .(9)
\end{aligned}
$$

Where $Y_{j, p-\tau}^{i}$ is the NSDP in the $j$ th industry of the $i$ th region at time $p-\tau$ i.e. at the beginning of the period and $Y_{j, p}$ is the NSDP in the $j$ th industry for the nation as a whole at time $p$ i.e. at the end of the period. We do the analysis for four distinct periods: 1971-1979 (part of the Period of controls and planning), 1979-1993 (the eighties of revival, partial reforms and unsustainable growth), 1993-2003 (the post reform period including the period of slow growth from 1997-200203), 2003-2010 (the period of recent high growth including the global financial crisis and (now aborted) "recovery").

Table 16 reports the results. The factors are reported as a ratio of the total growth i.e. $T F_{p}^{i}$.The first observation is that the "structural factors" have been high in the economy pointing to agglomeration and national market effects. The average values for the same across the states omitting Jammu and Kashmir (JK, because of the strong effects of insurgency both when it existed and when it was overcome) and Kerala (KE, possible effects of the spending of vast remittances from the Middle East and the stupendous growth of the services sector) much smaller than the "structural factor". This is as expected, since the basic diversification of the economy had taken place in the mid-sixties. If the more industrialized and largish states (WB, TN, MH, GJ, AP, KA, RJ, UP) are considered, then regional factors have been nearly neutral or just about positive for AP, and negative for all periods except the latest for GJ, negative or neutral for all periods except the 1993-2003 period for Karnataka. For Maharashtra, it has been very positive in the first period, neutral in the second period, negative in 
the immediate post reform period, and positive again in the last period. For Rajasthan only the second period was positive, others being negative or neutral. For Tamil Nadu it was negative in every period. For WB too it was so except over the period 1993-2003 when it was neutral. The two most highly industrialized states both show positive residual factor in the latest period. Thus even in Gujarat the structural factors have been very important in its high growth. Very recently though both Maharashtra and Gujarat have been able to enhance their residual (regional) factors for a variety of reasons including possibly continuing investor friendly regimes. Tamil Nadu and West Bengal and UP could not build on their endowments. Haryana unlike Punjab shows positive residual which we speculate is largely due to the spillover of development in Delhi which it was located well to catch. Delhi again shows positive or neutral residual factors since its growth would have been amply helped by the vast central government support, rent generating, and spending effects of it being the capital of the country. Orissa in the last period has shown strong regional effects since infrastructure and mining industries have accelerated in this period due to natural endowments.

Thus we would see that the race being to the productive leader between Maharashtra and Gujarat has not been decided. While Gujarat has maintained on its advantage in manufacturing, and agriculture Maharashtra continued to maintain its advantage in manufacturing and services. Land, infrastructure may be Gujarat's forte, but Maharashtra's is larger and cosmopolitan cities attracting FDI and tradable service industries, besides ample local availability of skills, attracting skill intensive industries.

Smaller states would show much larger (positive and negative values) in the "residual" since here the effect of local and idiosyncratic factors could be quite large. Bihar has shown a negative residual in every period except the last one perhaps reflective of the improvements in governance brought about by the government in recent years.

\section{Factors Underlying Regional Growth}

As mentioned earlier there are many factors that underlie regional growth. These may be classed into national level factors which working through the existing structure of the economy, and the structure of demand would in itself give rise to differences in the growth rates of regions. Other factors would emanate from those that are "controllable" or arise at the regional level. Thus provision of public services, local exogenous demand (agriculture) besides other idiosyncratic factors would be part of the second set. The idiosyncratic factors are not easily tested through cross sectional statistical analysis since they may not be easily captured by the data (governance for example) or even when the data is available there may not be sufficient variation over time (but only over the region) so that no more than one of these factors can be included in panel studies. The variables would therefore have to have sufficient variation over both time and space to work in the panel context. Variables that are missing for some states or some time periods would greatly reduce the overall number of observations as well. Hence we are constrained to use a very limited set of variables to explain the growth performance of states. We know that variations in agricultural output are a principal driver of variations in local demand over time. (Private final consumption expenditure growth is high correlated to growth in agricultural GDP at the national level, and private final consumption expenditure would drive demand for manufactured goods). Similarly we expect the service sector growth to be a driver of demand for manufacturing. Supply situation could have been specified by improvement in roads, communication, and electricity and many other infrastructural variables. Unfortunately, most except electricity sales are either not available as time series or there is not sufficient variation across time. It is important to use registered manufacturing NSDP since this is the most influenced by regional factors. Unregistered Mfg. is also so influenced but the data accumulation here is based on many imputations and so is not sufficiently reliable for year to year changes. Service industries being constituted to many industries and some of which are 
also gathered based on imputations have similar problems. Hence an indication of locally embedded growth that is also amenable to regression analysis is the output of the registered manufacturing sector.

Hence we carry out a regression as follows:

$\tilde{Y}_{\text {reg. } m f g, t}^{i}=\theta+\hat{\beta}_{1} \cdot \tilde{Y}_{\text {agri,t }}^{i}+\hat{\beta}_{2} \cdot \tilde{Y}_{\text {terti, },}^{i}+\hat{\beta}_{3} \cdot \tilde{E}_{t}^{i}+\varepsilon_{t}^{i}$

Where $\tilde{E}_{t}^{i}$ is the growth rate in electricity sales to the commercial and industrial sectors. The first two factors are reflective of demand and the second of public supply. We know that the electricity constraint has been severe in production and the variation in the same becomes a primary candidate for explanation of the cross section variations in manufacturing output.The regression produces meaningful results and the residues are randomly distributed so that other omitted factors would not disturb the findings based on the estimation of the limited model above. See table 17.

We further show that the regression improves if the national level growth is introduced as a variable. See Table 18, for the estimate of the equation below.

$\tilde{Y}_{\text {reg.mfg, }, t}^{i}=\hat{\alpha}_{Z} \cdot \tilde{Z}_{t}^{i}+\hat{\beta}_{1} \cdot \tilde{Y}_{\text {agri,t }}^{i}+\hat{\beta}_{2} \cdot \tilde{Y}_{\text {tertit, }}^{i}+\hat{\beta}_{3} \cdot \tilde{E}_{t}^{i}+\varepsilon_{t}^{i} \ldots$

wherein the constant is replaced by the national level growth rates.

Observe that all factors have the expected signs and are significant so that the conclusion that variations in the power situation as measured by the growth in the sales of electricity, and performance of (local) agriculture and services sectors through possibly the demand multiplier are important. This finding does not exclude the large influence of other idiosyncratic factors and of other factors, but nevertheless it establishes that local demand and local electricity sales growth are important.

Gujarat has shown one of the best performances of the electricity sector. It is the only state with a near $24 \times 7$ supply even in rural areas. (Morris, S. et al 2010). It has never shied to procure electricity through long term arrangements, has seen high growth in supply. The improvements have been particularly significant over the last eight years or so, so that we can conclude with much confidence that the electricity supply has been an important contributor to its high growth. We also know that the agricultural sector has seen a rapid growth in Gujarat, and so the second conclusion would be that the demand side effects of rapid agricultural growth have been positive on Gujarat. These conclusions have policy validly since both agricultural performance and electricity performance about which states can do much can therefore results in development not only of these sectors but of manufacturing as well, wherein the immediate and for quite a while the scope for growth is very large.

\section{Conclusion}

Growth rates of regions (states) have generally followed the national level growth rates over time with small lags or leads. We first estimate symmetric and reliable growth rates for periods (which are based on policy and other arguments). Explanations of performance of regions over time need to necessarily consider the performance of the nation, the phases and regimes therein, and the shocks that the economy has faced at the national level. We find much coherence between the aggregate performance of regions over time and that of the nation, so that the periodization at the national level is also useful at the regional level. Growth of regions since the reform of 1991-93 can be considered in two phases 1992-94 to 2002-03 and 2003-04 onwards. The very growth achieved in the latter period is mirrored at the regional level with particularly the services sector growth rate 
moving upwards in the second period. Gujarat like many other states is no exception. But its large competitive advantage in manufacturing means that the growth achieved in the manufacturing sector may have been less than what was possible given the monetary and exchange rate conservatism of the Reserve Bank of India.

While structural factors explain a larger part of the differential growth across regions and Gujarat is no exception, in the very last period both Maharashtra and Gujarat show strong positive residual (regional) factors explaining their high growth performance in this period. The contrast is with Tamil Nadu and West Bengal in the very same period.

What is remarkable though of Gujarat is that it has been able to maintain and enhance its comparative advantage despite a high level of per capita income. All other highly industrialized (and high income) states have as expected steadily lost their comparative advantage with per capita growth; which is reflective of labor costs for agriculture going up relatively in these regions. Besides water management efficiency, and supply of power more regularly (thanks to the Jyotigram Programme of the Government), the higher income inequality and vast migrations to Gujarat and the increasing use of capital intensive machinery in Gujarat may have allowed it hold on to its advantage, and the Narmada project and ample rainfall over the period may have enhanced the same as well.

The factors that explain regional industrial performance are many. But considering a limited set of those which are not idiosyncratic, and are validly considered in statistical analysis that use panel data models, it is possible to establish that performance of the electricity sector, of local agriculture of the tertiary sector (which through the demand multiplier effects of remittances and the exports of tradable services has been an engine) have also operated at the regional level. [Most certainly there are other factors as well which we could not formally consider in this study]. Different states score differently on these determining variables. Gujarat shows better performance on both agriculture and electricity but especially the latter which therefore inter alia has influenced local industrialization. But the roles of the factors considered must not be exaggerated since other factors like land (ease of providing the same for industries and cost), infrastructural performance, performance of urban centres and availability of skills locally, besides local governance (but especially its interface with industry) are important regional level determinants of states' performance. These factors unfortunately could not be tested given the difficulty with which information pertaining to these factors are cast in a way as to render panel studies meaningful.

The most important conclusion is that the coherence of national level growth with regional being high, the focus in discussions of the performance of states and state governments should shift to income distribution, performance of public services, locally provided infrastructure, social services over which state governments have far better and possibly even overriding control. 


\section{References}

Bagchi, Amiya; Panchanan Das, Sadan Chattopadhay (2005), "Growth and Structural Change in the Economy of Gujarat 1970-2000", Economic and Political Weekly, July 9, pp.3039-3047.

Dholakia, Ravindra (1994), "Spatial Dimension of Acceleration of Economic Growth in India", Economic and Political Weekly, Aug.27, pp.2203-2309.

Dholakia, Ravindra (2000), "Liberalisation in Gujarat: Review of Recent Experience", Economic and Political Weekly, Aug.26-Sept.8, pp.3121-3124.

Dholakia, Ravindra (2007), "Sources of Economic Growth and Acceleration in Gujarat", Economic and Political Weekly, Vol. 42, No. 9 (Mar. 3-9, 2007), pp. 770-778.

Gujarati, Damodar (1995), Basic Econometrics, McGraw Hill, Third Edition.

Hirway, Indira (1995), "Selective Development and Widening Disparities in Gujarat", Economic and Political Weekly, Oct. 14-21., pp.2603-2618.

Hirway, Indira (2000), "Dynamics of Development in Gujarat: Some Issues", Economic and Political Weekly, Aug 26 -Sept 8., pp.3106-3120

Joshi, Vijay and I.M.D. Little (1996), India's Economic Reforms -1991-2001, Oxford Univ. Press., New Delhi

Morris, Sebastian (2003), "Expenditure Accountability in India: The Interlinkages", in Morris, Sebastian (ed.), India Infrastructure Report, 2003- Public Expenditure Allocation and Accountability, 3iNetwork, Oxford Univ. Press, New Delhi.

Morris, Sebastian (2005), "Understanding Export Led Growth and Late Industrialisation to Explain the Differences in the Post Reform Performance of India and China", WP No. 2005/03/02, Indian Institute of Management Ahmedabad; and pp. 41-62, in "Proceedings of the International Conference on economic Reforms in India and China: Emerging Issues and Challenges, Indira Gandhi Institute of Development Research, Mumbai India; and China Development Institute, PR China.

Morris, Sebastian (2006a), Chapter I: Economic Performance of Gujarat in Recent Times in Planning Commission and Gujarat Institute of Development Research, Report on Economic Development of Gujarat.

Morris, Sebastian (2006a), Chapter 2: Infrastructural Development in Gujarat, in Planning Commission and Gujarat Institute of Development Research, Report on Economic Development of Gujarat.

Morris, Sebastian (2007), "Agriculture: A Perspective from History, the Metrics of Comparative Advantage, and Limitations of the Market to Understand the Role of State in a Globalising World", W.P. No.2007-02-02, February 2007, Indian Institute of Management Ahmedabad.

Morris, Sebastian; Ajay Pandey, Sobesh Agarwalla and M.S. Sriram (2010), Impact Assessment of the Jyotigram Programme of the Government of Gujarat (Final Report), Indian Institute of Management Ahmedabad, 30th December. 
Nagaraj, R. (2000), "Indian Economy since 1980: Virtuous Growth or Polarisation", Vol. 35, No. 32 (Aug. 5-11, 2000), pp. 2831-2833+2835-2839, Economic and Political Weekly (URL: http://www.jstor.org/stable/4409590 .Accessed: 18/11/2012 23:58)

Robinson, E.A.G. (1994) "Economic Consequences of the Size of Nations (Lisbon, Portugal, 1957), edited by E.A.G. Robinson, Macmillan 1960.

Varma, J.R. (2009), "Indian Financial Sector and Global Financial Crisis", Vikalpa, Sept., Vol 34, No.3, pp. 25-34. 


\begin{tabular}{|l|l|l|}
\hline \multicolumn{2}{|l|}{ Table 1: Distinct Periods of Growth and Policy Since the Reform of 1991-92 and 1992-93 } & $\begin{array}{l}\text { Growth } \\
\text { Achieved } \\
\text { (approx..) }\end{array}$ \\
\hline Period /year & Characterization \\
\hline $1993-94-98$ & $\begin{array}{l}\text { Post reform high growth, export and private investment led, flexible } \\
\text { monetary stance, higher agricultural growth rate }\end{array}$ & $6.7 \%$ \\
\hline $1998-99-$ & $\begin{array}{l}\text { Slow down, slowing private investment (little clarity on infrastructure forms } \\
\text { and policy), post east Asian crisis effect, very conservative monetary policy } \\
\text {-money supply growth less than 13\% on average, capital flow volatility } \\
\text { could be contained by sterilization fiscal policy too somewhat conservative }\end{array}$ & $5.25 \%$ \\
\hline $2003-04-$ & $\begin{array}{l}\text { Rapid growth, kick started by GQ spending, continued by revival of exports } \\
\text { on global growth, enhanced by large increases in service exports, and } \\
\text { remittances. Large capital inflows initially accommodated, limits of } \\
\text { sterilization reached so money growth rises to 17\% or more from 2004-05, } \\
\text { later reigned in through increase in CRR and rupee appreciation, growth } \\
\text { comes down at end of period. High supply side inflation in second half of } \\
\text { period. }\end{array}$ & \\
\hline $\begin{array}{l}\text { Global recession, dollar and rupee liquidity crisis and then recovery of } \\
\text { liquidity; sharp braking of economy }\end{array}$ & $4.5 \% ?$ \\
\hline $\begin{array}{l}\text { Arrested revival, strong revival on fiscal stimulus, withdrawl of stimulus and } \\
\text { monetary tightening at end of period }\end{array}$ & $7.6 \%$ \\
\hline $2010-11$ & Continuing tightening, investment collapse and growth falls to less than 5\% & $<5.0 \% ?$ \\
\hline
\end{tabular}

Table 2: Estimated "Average" Growth Rates of the Nation When Seen as Constituted of States with Equal Weight through a Regression Using Time Dummies

\begin{tabular}{|c|c|c|c|c|c|c|c|c|}
\hline \multirow[t]{2}{*}{ Year } & \multicolumn{2}{|c|}{ NSDP at FC } & \multicolumn{2}{|c|}{ Agriculture } & \multicolumn{2}{|c|}{ Manufacturing } & \multicolumn{2}{|c|}{ All Teritary } \\
\hline & Coeff.(\$) & Sig. & Coeffi.(\$) & Sig. & Coeff.(\$) & Sig. & Coeff.(\$) & Sig. \\
\hline \multicolumn{9}{|l|}{1961} \\
\hline 1962 & $1.4 \%$ & & $1.2 \%$ & & & & $1.7 \%$ & \\
\hline 1963 & $1.2 \%$ & & $-4.5 \%$ & & & & $1.3 \%$ & \\
\hline 1964 & $5.0 \%$ & & $2.2 \%$ & & & & $2.9 \%$ & \\
\hline 1965 & $6.8 \%$ & & $11.1 \%$ & & & & $4.6 \%$ & \\
\hline 1966 & $-6.0 \%$ & & $-23.2 \%$ & $* * *$ & & & $-2.8 \%$ & \\
\hline 1967 & $2.6 \%$ & & $-5.2 \%$ & & & & $1.0 \%$ & \\
\hline 1968 & $9.1 \%$ & $* *$ & $24.8 \%$ & $* * *$ & & & $5.7 \%$ & \\
\hline 1969 & $-4.3 \%$ & & $-9.1 \%$ & & & & $-0.3 \%$ & \\
\hline 1970 & $4.0 \%$ & & $7.6 \%$ & & & & $4.3 \%$ & \\
\hline 1971 & $5.0 \%$ & & $1.6 \%$ & & $3.4 \%$ & & $4.3 \%$ & $* * *$ \\
\hline 1972 & $3.6 \%$ & $* *$ & $-7.9 \%$ & $* * *$ & $4.8 \%$ & & $2.0 \%$ & \\
\hline 1973 & $-1.2 \%$ & & $10.1 \%$ & $* * *$ & $4.9 \%$ & & $3.7 \%$ & $* * *$ \\
\hline 1974 & $5.4 \%$ & $* * *$ & $-2.9 \%$ & & $3.2 \%$ & & $1.2 \%$ & \\
\hline 1975 & $0.2 \%$ & & $11.3 \%$ & $* * *$ & $5.3 \%$ & & $7.7 \%$ & $* * *$ \\
\hline 1976 & $7.7 \%$ & $* * *$ & $-4.2 \%$ & & $10.9 \%$ & $* * *$ & $5.3 \%$ & $* * *$ \\
\hline 1977 & $3.5 \%$ & $* *$ & $9.2 \%$ & $* * *$ & $3.8 \%$ & & $7.6 \%$ & $* * *$ \\
\hline 1978 & $6.3 \%$ & $* * *$ & $1.8 \%$ & & $7.7 \%$ & $* *$ & $4.6 \%$ & $* * *$ \\
\hline 1979 & $4.8 \%$ & $* * *$ & $-11.3 \%$ & $* * *$ & $3.9 \%$ & & $3.0 \%$ & $* *$ \\
\hline 1980 & $-1.5 \%$ & & $10.7 \%$ & $* * *$ & $5.5 \%$ & & $4.9 \%$ & $* * *$ \\
\hline 1981 & $4.5 \%$ & $* * *$ & $5.1 \%$ & $* *$ & $6.7 \%$ & $* *$ & $4.4 \%$ & $* * *$ \\
\hline 1982 & $7.6 \%$ & $* * *$ & $-1.6 \%$ & & $11.5 \%$ & $* * *$ & $6.1 \%$ & $* * *$ \\
\hline 1983 & $1.2 \%$ & & $8.1 \%$ & $* * *$ & $6.7 \%$ & $* *$ & $2.3 \%$ & $*$ \\
\hline 1984 & $3.1 \%$ & $* *$ & $1.8 \%$ & & $4.5 \%$ & & $4.3 \%$ & $* * *$ \\
\hline 1985 & $2.9 \%$ & $*$ & $2.7 \%$ & & $1.9 \%$ & & $5.4 \%$ & $* * *$ \\
\hline 1986 & $5.1 \%$ & $* * *$ & $-1.6 \%$ & & $2.8 \%$ & & $6.5 \%$ & $* * *$ \\
\hline 1987 & $2.0 \%$ & & $-2.5 \%$ & & $8.5 \%$ & $* * *$ & $6.0 \%$ & $* * *$ \\
\hline 1988 & $-1.8 \%$ & & $14.2 \%$ & $* * *$ & $9.8 \%$ & $* * *$ & $4.1 \%$ & $* * *$ \\
\hline
\end{tabular}




\begin{tabular}{|l|l|l|l|l|l|l|l|l|}
\hline 1989 & $11.2 \%$ & $* * *$ & $3.2 \%$ & & $5.6 \%$ & $*$ & $6.5 \%$ & $* * *$ \\
\hline 1990 & $2.9 \%$ & $*$ & $2.6 \%$ & & $8.7 \%$ & $* * *$ & $5.2 \%$ & $* * *$ \\
\hline 1991 & $3.9 \%$ & $* *$ & $0.7 \%$ & & $2.5 \%$ & & $4.6 \%$ & $* * *$ \\
\hline 1992 & $0.3 \%$ & & $4.6 \%$ & $*$ & $6.1 \%$ & $*$ & $6.3 \%$ & $* * *$ \\
\hline 1993 & $5.1 \%$ & $* * *$ & $1.0 \%$ & & $4.6 \%$ & & $5.2 \%$ & $* * *$ \\
\hline 1994 & $3.3 \%$ & $* *$ & $3.2 \%$ & & $9.4 \%$ & $* * *$ & $5.4 \%$ & $* * *$ \\
\hline 1995 & $5.8 \%$ & $* * *$ & $-1.9 \%$ & & $2.2 \%$ & & $6.0 \%$ & $* * *$ \\
\hline 1996 & $3.8 \%$ & $* * *$ & $5.8 \%$ & $* *$ & $9.2 \%$ & $* * *$ & $7.2 \%$ & $* * *$ \\
\hline 1997 & $6.2 \%$ & $* * *$ & $-1.8 \%$ & & $9.8 \%$ & $* * *$ & $9.0 \%$ & $* * *$ \\
\hline 1998 & $4.6 \%$ & $* * *$ & $4.7 \%$ & $* *$ & $-11.0 \%$ & $* * *$ & $5.5 \%$ & $* * *$ \\
\hline 1999 & $3.5 \%$ & $* *$ & $0.4 \%$ & & $0.6 \%$ & & $5.8 \%$ & $* * *$ \\
\hline 2000 & $1.9 \%$ & & $-0.5 \%$ & & $2.3 \%$ & & $4.6 \%$ & $* * *$ \\
\hline 2001 & $3.7 \%$ & $* * *$ & $6.0 \%$ & $* * *$ & $-3.9 \%$ & & $5.5 \%$ & $* * *$ \\
\hline 2002 & $4.0 \%$ & $* * *$ & $-4.5 \%$ & $* *$ & $9.8 \%$ & $* * *$ & $5.4 \%$ & $* * *$ \\
\hline 2003 & $4.7 \%$ & $* * *$ & $9.4 \%$ & $* * *$ & $8.7 \%$ & $* * *$ & $6.2 \%$ & $* * *$ \\
\hline 2004 & $7.2 \%$ & $* * *$ & $1.7 \%$ & & $8.8 \%$ & $* * *$ & $7.7 \%$ & $* * *$ \\
\hline 2005 & $6.8 \%$ & $* * *$ & $3.2 \%$ & & $5.3 \%$ & $*$ & $8.8 \%$ & $* * *$ \\
\hline 2006 & $7.5 \%$ & $* * *$ & $4.1 \%$ & $*$ & $15.4 \%$ & $* * *$ & $9.8 \%$ & $* * *$ \\
\hline 2007 & $9.3 \%$ & $* * *$ & $6.1 \%$ & $* * *$ & $11.9 \%$ & $* * *$ & $9.4 \%$ & $* * *$ \\
\hline 2008 & $8.4 \%$ & $* * *$ & $0.9 \%$ & & $2.3 \%$ & & $9.6 \%$ & $* * *$ \\
\hline 2009 & $6.8 \%$ & $* * *$ & $1.8 \%$ & & $6.8 \%$ & $* *$ & $11.3 \%$ & $* * *$ \\
\hline 2010 & $8.4 \%$ & $* * *$ & & & & & & \\
\hline 2011 & & & & & & & & \\
\hline$*$ Sig at $10 \%, * *$ at $5 \% * * *$ & at $1 \%$ & & & & \\
\hline (1) Can be interpreted as year wise growth rate for the panel. & & & & & $*$ \\
\hline
\end{tabular}

Table 3: Regression of State Level NSDP Growth Rate on National Level GDP Growth Rate and Interaction with Period Dummies

\begin{tabular}{|l|l|l|l|l|l|l|}
\hline Variable & In Eq. & Coefficient & Std. Error & t-ratio & P-value & Sign. \\
\hline Constant & $\hat{\theta}$ & 0.0049 & 0.0053 & 0.9253 & 0.3550 & \\
\hline NSDP growth rate & $\hat{\beta}_{0}$ & 0.9522 & 0.1646 & 5.7860 & 0.0000 & $* * *$ \\
\hline Inter Dummy 1979 & $\hat{\beta}_{1}$ & -0.2501 & 0.1577 & -1.5860 & 0.1131 & \\
\hline Inter Dummy 1993 & $\hat{\beta}_{2}$ & -0.3632 & 0.1547 & -2.3480 & 0.0191 & $* *$ \\
\hline Inter Dummy 2003 & $\hat{\beta}_{3}$ & -0.0514 & 0.1520 & -0.3383 & 0.7352 & \\
\hline R-squared & & 0.0873 & Adjusted R-squared & 0.0838 & \\
\hline $\mathrm{F}(4,1058)$ & & 25.2970 & P-value(F) & $4.89 \mathrm{E}-20$ & \\
\hline
\end{tabular}




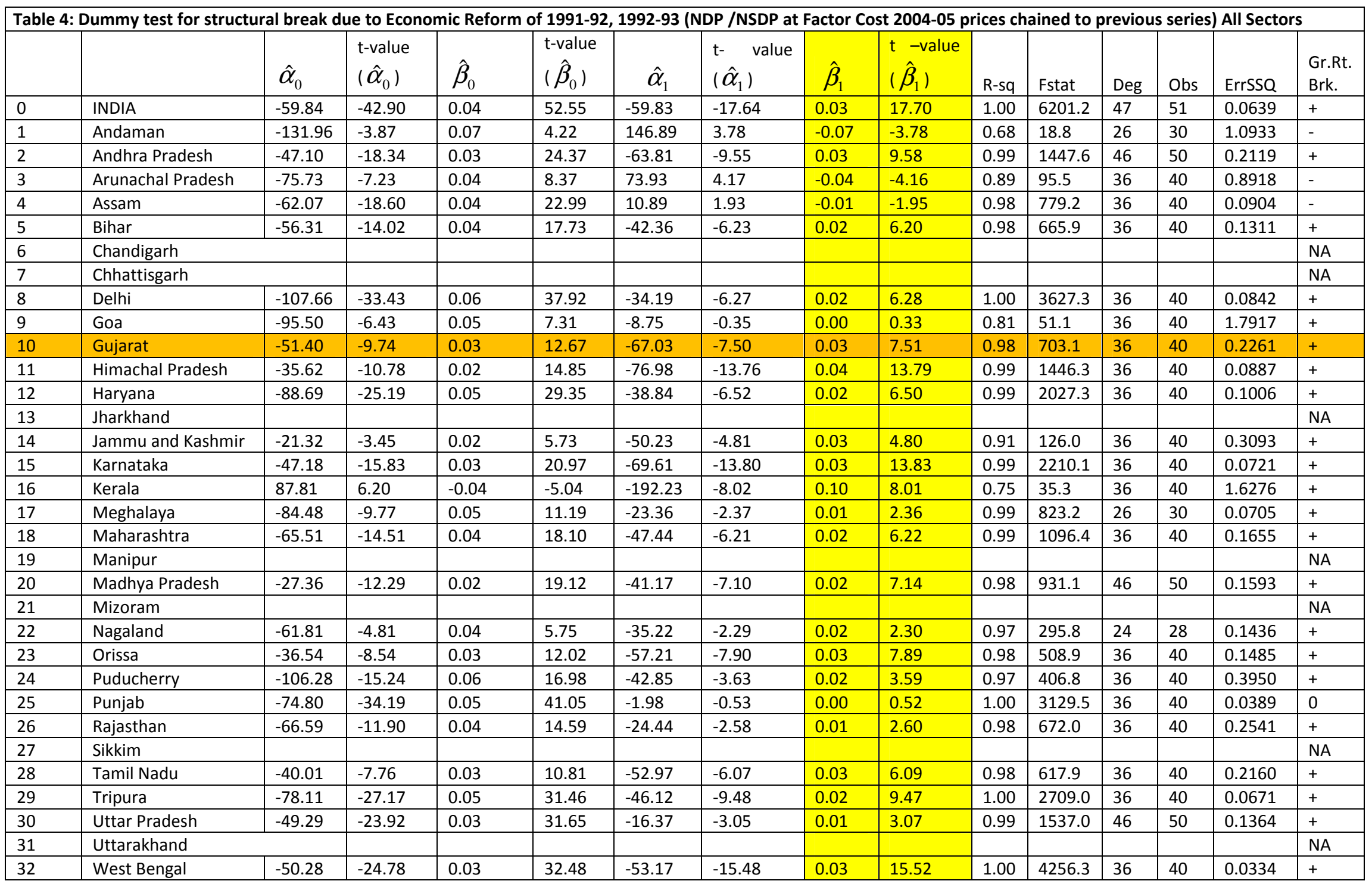




\begin{tabular}{|c|c|c|c|c|c|c|c|c|c|c|c|c|c|c|c|}
\hline & & Cons. & $t$ (Cons.) & b1 & $\mathrm{t}(\mathrm{b} 1)$ & b2 & $t(b 2)$ & b3 & $t(b 3)$ & R-sq & Fstat & Deg. & Obs & ErrSSQ & $\begin{array}{l}\text { Gr.Rt. } \\
\text { Brk. }\end{array}$ \\
\hline 0 & INDIA & -38.18 & -19.56 & 0.03 & 25.85 & -4.28 & -0.90 & 0.00 & 0.92 & 0.99 & 1085.9 & 47 & 51 & 0.1251 & 0 \\
\hline 1 & Andaman & $\begin{array}{l}-59.91 \\
\end{array}$ & -3.93 & 0.04 & 4.56 & 91.93 & 5.28 & -0.05 & -5.27 & 0.72 & 22.3 & 26 & 30 & 0.2195 & - \\
\hline 2 & Andhra Pradesh & -28.57 & -8.37 & 0.02 & 12.63 & -30.09 & -3.39 & 0.02 & 3.40 & 0.95 & 292.2 & 46 & 50 & 0.3742 & + \\
\hline 3 & Arunachal Pradesh & -150.59 & -28.76 & 0.08 & 30.60 & 84.59 & 9.54 & -0.04 & -9.56 & 0.99 & 1090.4 & 36 & 40 & 0.2226 & - \\
\hline 4 & Assam & -35.65 & -13.19 & 0.02 & 18.18 & 26.23 & 5.73 & -0.01 & -5.74 & 0.97 & 400.5 & 36 & 40 & 0.0593 & - \\
\hline 5 & Bihar & -18.11 & -2.65 & 0.02 & 4.72 & -24.59 & -2.13 & 0.01 & 2.11 & 0.73 & 32.1 & 36 & 40 & 0.3789 & + \\
\hline 6 & Chandigarh & & & & & & & & & & & & & & NA \\
\hline 7 & Chhattisgarh & & & & & & & & & & & & & & NA \\
\hline 8 & Delhi & -26.30 & -2.05 & 0.02 & 2.99 & 101.00 & 4.64 & -0.05 & -4.67 & 0.72 & 30.2 & 36 & 40 & 1.3408 & - \\
\hline 9 & Goa & -24.29 & -3.83 & 0.02 & 5.49 & 15.89 & 1.48 & -0.01 & -1.48 & 0.83 & 59.5 & 36 & 40 & 0.3259 & 0 \\
\hline 10 & Gujarat & -19.65 & -1.20 & 0.02 & 2.05 & -33.92 & -1.22 & 0.02 & 1.22 & 0.64 & 21.4 & 36 & 40 & 2.1912 & 0 \\
\hline 11 & Himachal Pradesh & -39.21 & -6.42 & 0.03 & 8.42 & -15.37 & -1.49 & 0.01 & 1.48 & 0.92 & 141.5 & 36 & 40 & 0.3032 & 0 \\
\hline 12 & Haryana & -56.10 & -11.07 & 0.04 & 13.78 & 26.49 & 3.09 & -0.01 & -3.08 & 0.96 & 315.2 & 36 & 40 & 0.2084 & - \\
\hline 13 & Jharkand & & & & & & & & & & & & & & NA \\
\hline 14 & Jammu and Kashmir & -38.95 & -9.25 & 0.03 & 12.20 & -12.94 & -1.82 & 0.01 & 1.83 & 0.97 & 434.7 & 36 & 40 & 0.1438 & 0 \\
\hline 15 & Karnataka & -34.82 & -6.45 & 0.02 & 9.06 & 8.85 & 0.97 & 0.00 & -0.95 & 0.95 & 213.7 & 36 & 40 & 0.2364 & 0 \\
\hline 17 & Meghalaya & -16.22 & -1.55 & 0.01 & 2.59 & -79.70 & -6.69 & 0.04 & 6.67 & 0.96 & 227.3 & 26 & 30 & 0.1028 & + \\
\hline 18 & Maharashtra & -43.21 & -5.28 & 0.03 & 7.00 & -17.12 & -1.24 & 0.01 & 1.25 & 0.93 & 171.6 & 36 & 40 & 0.5442 & 0 \\
\hline 19 & Manipur & & & & & & & & & & & & & & NA \\
\hline 20 & Madhya Pradesh & -30.28 & -5.57 & 0.02 & 8.16 & 10.05 & 0.71 & 0.00 & -0.70 & 0.88 & 112.4 & 46 & 50 & 0.9484 & 0 \\
\hline 21 & Mizoram & & & & & & & & & & & & & & NA \\
\hline 22 & Nagaland & -49.50 & -2.78 & 0.03 & 3.37 & -160.46 & -7.56 & 0.08 & 7.55 & 0.98 & 321.6 & 24 & 28 & 0.2749 & + \\
\hline 23 & Orissa & -19.48 & -2.51 & 0.02 & 4.31 & 5.50 & 0.42 & 0.00 & -0.43 & 0.51 & 12.5 & 36 & 40 & 0.4876 & - \\
\hline 24 & Puducherry & 34.15 & 5.08 & -0.01 & -3.57 & -33.13 & -2.91 & 0.02 & 2.92 & 0.32 & 5.7 & 36 & 40 & 0.3673 & + \\
\hline 25 & Punjab & -70.29 & -34.71 & 0.04 & 41.67 & 45.50 & 13.28 & -0.02 & -13.28 & 0.99 & 2278.1 & 36 & 40 & 0.0333 & - \\
\hline 26 & Rajasthan & -40.09 & -3.83 & 0.03 & 5.17 & 6.07 & 0.34 & 0.00 & -0.33 & 0.86 & 71.8 & 36 & 40 & 0.8899 & - \\
\hline 27 & Sikkim & & & & & & & & & & & & & & NA \\
\hline 28 & Tamil Nadu & -6.80 & -0.83 & 0.01 & 2.54 & -2.83 & -0.20 & 0.00 & 0.22 & 0.82 & 53.1 & 36 & 40 & 0.5456 & 0 \\
\hline 29 & Tripura & -47.01 & -9.56 & 0.03 & 11.87 & -37.97 & -4.56 & 0.02 & 4.55 & 0.97 & 357.3 & 36 & 40 & 0.1962 & + \\
\hline 30 & Uttar Pradesh & -34.23 & -12.20 & 0.02 & 17.55 & 12.35 & 1.69 & -0.01 & -1.69 & 0.96 & 394.7 & 46 & 50 & 0.2527 & 0 \\
\hline 31 & Utarakhand & & & & & & & & & & & & & & NA \\
\hline 32 & West Bengal & -67.28 & -14.33 & 0.04 & 17.36 & 30.81 & 3.88 & -0.02 & -3.86 & 0.98 & 585.3 & 36 & 40 & 0.1790 & - \\
\hline
\end{tabular}




\begin{tabular}{|c|c|c|c|c|c|c|c|c|c|c|c|c|c|c|c|}
\hline & & Cons. & $t$ (Cons.) & b1 & $t(b 1)$ & b2 & $t(b 2)$ & b3 & $t(b 3)$ & $R-s q$ & Fstat & Deg. & Obs & ErrSSQ & $\begin{array}{l}\text { Gr.Rt. } \\
\text { Brk. }\end{array}$ \\
\hline 0 & INDIA & -78.57 & -46.18 & 0.05 & 52.94 & -46.52 & -11.25 & 0.02 & 11.28 & 1.00 & 5175.8 & 47 & 51 & 0.0950 & + \\
\hline 1 & Andaman & -111.08 & -4.32 & 0.06 & 4.59 & 81.68 & 2.79 & -0.04 & -2.78 & 0.89 & 68.7 & 26 & 30 & 0.6217 & - \\
\hline 2 & Andhra Pradesh & -109.29 & -28.90 & 0.06 & 32.24 & 17.53 & 1.78 & -0.01 & -1.76 & 0.99 & 1576.8 & 46 & 50 & 0.4595 & 0 \\
\hline 3 & Arunachal Pradesh & -184.41 & -22.32 & 0.10 & 23.22 & 125.57 & 8.98 & -0.06 & -8.98 & 0.98 & 626.6 & 36 & 40 & 0.5544 & - \\
\hline 4 & Assam & -70.02 & -5.31 & 0.04 & 6.24 & 26.90 & 1.21 & -0.01 & -1.22 & 0.76 & 38.1 & 36 & 40 & 1.4098 & 0 \\
\hline 5 & Bihar & -108.95 & -9.46 & 0.06 & 10.54 & 92.40 & 4.74 & -0.05 & -4.77 & 0.82 & 54.9 & 36 & 40 & 1.0758 & - \\
\hline 6 & Chandigarh & & & & & & & & & & & & & & NA \\
\hline 7 & Chhattisgarh & & & & & & & & & & & & & & NA \\
\hline 8 & Delhi & -160.18 & -25.95 & 0.09 & 27.87 & 69.24 & 6.63 & -0.03 & -6.64 & 0.99 & 994.4 & 36 & 40 & 0.3094 & - \\
\hline 9 & Goa & -170.07 & -15.32 & 0.09 & 16.27 & -4.84 & -0.26 & 0.00 & 0.25 & 0.98 & 484.0 & 36 & 40 & 1.0011 & 0 \\
\hline 10 & Gujarat & -114.47 & -14.11 & 0.06 & 15.78 & -5.59 & -0.41 & 0.00 & 0.42 & 0.98 & 605.3 & 36 & 40 & 0.5344 & 0 \\
\hline 11 & Himachal Pradesh & -146.55 & -10.37 & 0.08 & 11.06 & -2.32 & -0.10 & 0.00 & 0.12 & 0.97 & 392.3 & 36 & 40 & 1.6217 & 0 \\
\hline 12 & Haryana & -154.75 & -45.16 & 0.08 & 48.88 & 40.28 & 6.94 & -0.02 & -6.97 & 1.00 & 3429.4 & 36 & 40 & 0.0953 & - \\
\hline 13 & Jharkhand & & & & & & & & & & & & & & NA \\
\hline 14 & Jammu and Kashmir & -110.11 & -10.79 & 0.06 & 11.86 & 32.69 & 1.89 & -0.02 & -1.91 & 0.92 & 135.4 & 36 & 40 & 0.8455 & - \\
\hline 15 & Karnataka & -126.87 & -20.90 & 0.07 & 23.08 & 24.16 & 2.35 & -0.01 & -2.36 & 0.99 & 887.4 & 36 & 40 & 0.2993 & - \\
\hline 17 & Meghalaya & -136.63 & -2.78 & 0.07 & 2.94 & -111.06 & -1.98 & 0.06 & 1.97 & 0.91 & 85.0 & 26 & 30 & 2.2799 & + \\
\hline 18 & Maharashtra & -94.73 & -13.21 & 0.06 & 15.25 & -1.47 & -0.12 & 0.00 & 0.12 & 0.98 & 495.4 & 36 & 40 & 0.4172 & 0 \\
\hline 19 & Manipur & & & & & & & & & & & & & & $\mathrm{NA}$ \\
\hline 20 & Madhya Pradesh & -90.45 & -18.88 & 0.05 & 21.49 & 32.44 & 2.60 & -0.02 & -2.59 & 0.98 & 608.0 & 46 & 50 & 0.7375 & - \\
\hline 21 & Mizoram & & & & & & & & & & & & & & NA \\
\hline 22 & Nagaland & -19.82 & -0.26 & 0.01 & 0.38 & 191.50 & 2.07 & -0.10 & -2.06 & 0.30 & 3.5 & 24 & 28 & 5.2317 & - \\
\hline 23 & Orissa & -38.70 & -3.14 & 0.03 & 4.14 & -113.81 & -5.46 & 0.06 & 5.45 & 0.88 & 88.4 & 36 & 40 & 1.2323 & + \\
\hline 24 & Puducherry & -97.16 & -5.45 & 0.05 & 6.00 & -149.79 & -4.96 & 0.08 & 4.97 & 0.95 & 210.5 & 36 & 40 & 2.5828 & + \\
\hline 25 & Punjab & -155.68 & -31.19 & 0.08 & 33.70 & 53.92 & 6.38 & -0.03 & -6.39 & 0.99 & 1679.1 & 36 & 40 & 0.2023 & - \\
\hline 26 & Rajasthan & -44.07 & -6.22 & 0.03 & 8.06 & -57.14 & -4.77 & 0.03 & 4.79 & 0.97 & 357.7 & 36 & 40 & 0.4071 & + \\
\hline 27 & Sikkim & & & & & & & & & & & & & & NA \\
\hline 28 & Tamil Nadu & -67.55 & -9.48 & 0.04 & 11.48 & -4.93 & -0.41 & 0.00 & 0.40 & 0.95 & 229.9 & 36 & 40 & 0.4121 & 0 \\
\hline 29 & Tripura & -109.88 & -5.52 & 0.06 & 5.98 & 45.28 & 1.34 & -0.02 & -1.35 & 0.78 & 41.7 & 36 & 40 & 3.2164 & 0 \\
\hline 30 & Uttar Pradesh & -107.48 & -22.44 & 0.06 & 25.27 & 65.07 & 5.22 & -0.03 & -5.23 & 0.98 & 647.8 & 46 & 50 & 0.7366 & - \\
\hline 31 & Uttarakhand & & & & & & & & & & & & & & $\mathrm{NA}$ \\
\hline 32 & West Bengal & -29.57 & -12.50 & 0.02 & 18.13 & -81.74 & -20.41 & 0.04 & 20.43 & 0.99 & 2325.4 & 36 & 40 & 0.0455 & + \\
\hline
\end{tabular}




\begin{tabular}{|c|c|c|c|c|c|c|c|c|c|c|c|c|c|c|c|}
\hline & & Cons. & $t$ (Cons.) & b1 & $\mathrm{t}(\mathrm{b} 1)$ & b2 & $t(b 2)$ & b3 & $t(b 3)$ & $\mathrm{R}-\mathrm{sq}$ & Fstat & Deg. & Obs. & ErrSSQ & $\begin{array}{l}\text { Gr.Rt.B } \\
\text { rk. }\end{array}$ \\
\hline 0 & INDIA & -83.91 & -53.27 & 0.05 & 61.18 & -65.87 & -17.20 & 0.03 & 17.26 & 1.00 & 7873.4 & 47 & 51 & 0.0814 & + \\
\hline 1 & Andaman & -136.08 & -4.50 & 0.07 & 4.83 & 90.02 & 2.61 & -0.04 & -2.59 & 0.93 & 122.7 & 26 & 30 & 0.8623 & - \\
\hline 2 & Andhra Pradesh & -82.30 & -23.60 & 0.05 & 27.73 & -56.63 & -6.24 & 0.03 & 6.26 & 0.99 & 1448.5 & 46 & 50 & 0.3906 & + \\
\hline 3 & $\begin{array}{l}\text { Arunachal } \\
\text { Pradesh }\end{array}$ & -185.31 & -30.96 & 0.10 & 32.56 & 50.19 & 4.95 & -0.03 & -4.95 & 0.99 & 1772.2 & 36 & 40 & 0.2909 & - \\
\hline 4 & Assam & -77.26 & -21.25 & 0.05 & 25.00 & -7.43 & -1.21 & 0.00 & 1.20 & 0.99 & 1223.6 & 36 & 40 & 0.1073 & 0 \\
\hline 5 & Bihar & -92.64 & -22.03 & 0.05 & 25.35 & -34.80 & -4.89 & 0.02 & 4.86 & 0.99 & 1279.4 & 36 & 40 & 0.1436 & + \\
\hline 6 & Chandigarh & & & & & & & & & & & & & & NA \\
\hline 7 & Chhattisgarh & & & & & & & & & & & & & & NA \\
\hline 8 & Delhi & -113.28 & -39.82 & 0.06 & 44.78 & -41.66 & -8.65 & 0.02 & 8.67 & 1.00 & 5415.6 & 36 & 40 & 0.0657 & + \\
\hline 9 & Goa & -89.80 & -14.26 & 0.05 & 16.12 & -16.41 & -1.54 & 0.01 & 1.55 & 0.98 & 730.1 & 36 & 40 & 0.3222 & 0 \\
\hline 10 & Gujarat & -93.02 & -32.92 & 0.05 & 38.01 & -58.31 & -12.19 & 0.03 & 12.20 & 1.00 & 4213.2 & 36 & 40 & 0.0648 & + \\
\hline 11 & Himachal Pradesh & -93.36 & -32.98 & 0.05 & 37.25 & -48.90 & -10.21 & 0.02 & 10.20 & 1.00 & 3706.7 & 36 & 40 & 0.0651 & + \\
\hline 12 & Haryana & -125.24 & -42.75 & 0.07 & 47.32 & -67.12 & -13.54 & 0.03 & 13.51 & 1.00 & 5454.7 & 36 & 40 & 0.0697 & + \\
\hline 13 & Jharkhand & & & & & & & & & & & & & & NA \\
\hline 14 & $\begin{array}{l}\text { Jammu and } \\
\text { Kashmir }\end{array}$ & -69.77 & -36.11 & 0.04 & 42.66 & -31.82 & -9.73 & 0.02 & 9.75 & 1.00 & 5227.8 & 36 & 40 & 0.0303 & + \\
\hline 15 & Karnataka & -91.45 & -39.37 & 0.05 & 45.50 & -68.33 & -17.38 & 0.03 & 17.40 & 1.00 & 6984.9 & 36 & 40 & 0.0438 & + \\
\hline 16 & Kerala & 110.78 & 5.89 & -0.05 & -5.03 & -247.38 & -7.77 & 0.12 & 7.75 & 0.79 & 45.5 & 36 & 40 & 2.8693 & + \\
\hline 17 & Meghalaya & -125.47 & -31.56 & 0.07 & 34.46 & 21.64 & 4.77 & -0.01 & -4.78 & 1.00 & 4599.6 & 26 & 30 & 0.0149 & - \\
\hline 18 & Maharashtra & -84.73 & -24.42 & 0.05 & 28.86 & -58.62 & -9.98 & 0.03 & 10.00 & 1.00 & 2773.5 & 36 & 40 & 0.0978 & + \\
\hline 19 & Manipur & & & & & & & & & & & & & & NA \\
\hline 20 & Madhya Pradesh & -58.91 & -20.48 & 0.04 & 25.35 & -30.60 & -4.09 & 0.02 & 4.11 & 0.99 & 1227.6 & 46 & 50 & 0.2658 & - \\
\hline 21 & Mizoram & & & & & & & & & & & & & & NA \\
\hline 22 & Nagaland & -60.03 & -6.43 & 0.04 & 7.66 & -39.05 & -3.50 & 0.02 & 3.50 & 0.98 & 466.4 & 24 & 28 & 0.0757 & + \\
\hline 23 & Orissa & -74.59 & -19.42 & 0.04 & 22.96 & -64.18 & -9.87 & 0.03 & 9.88 & 0.99 & 1728.3 & 36 & 40 & 0.1197 & + \\
\hline 24 & Puducherry & -69.62 & -18.84 & 0.04 & 21.73 & -113.50 & -18.15 & 0.06 & 18.19 & 1.00 & 3044.7 & 36 & 40 & 0.1109 & + \\
\hline 25 & Punjab & -77.99 & -33.18 & 0.05 & 39.17 & -18.06 & -4.54 & 0.01 & 4.51 & 1.00 & 2896.3 & 36 & 40 & 0.0449 & + \\
\hline 26 & Rajasthan & -94.60 & -20.74 & 0.05 & 23.82 & -15.36 & -1.99 & 0.01 & 2.00 & 0.99 & 1361.3 & 36 & 40 & 0.1690 & + \\
\hline 27 & Sikkim & & & & & & & & & & & & & & NA \\
\hline 28 & Tamil Nadu & -53.18 & -10.38 & 0.03 & 13.28 & -92.63 & -10.68 & 0.05 & 10.70 & 0.99 & 1045.8 & 36 & 40 & 0.2131 & + \\
\hline 29 & Tripura & -105.22 & -25.86 & 0.06 & 28.62 & -35.13 & -5.10 & 0.02 & 5.12 & 0.99 & 2269.6 & 36 & 40 & 0.1345 & + \\
\hline 30 & Uttar Pradesh & -60.46 & -26.32 & 0.04 & 32.84 & -22.34 & -3.74 & 0.01 & 3.75 & 0.99 & 1731.8 & 46 & 50 & 0.1695 & + \\
\hline 31 & Uttarakhand & & & & & & & & & & & & & & NA \\
\hline 32 & West Bengal & -72.79 & -47.20 & 0.04 & 56.79 & -60.65 & -23.23 & 0.03 & 23.26 & 1.00 & 11159.0 & 36 & 40 & 0.0193 & + \\
\hline
\end{tabular}




\begin{tabular}{|c|c|c|c|c|c|c|c|c|c|c|}
\hline & \multicolumn{3}{|c|}{ Coefficients } & \multicolumn{3}{|l|}{ t-ratios } & \multirow[t]{2}{*}{ R-sq } & \multirow{2}{*}{$\begin{array}{l}\text { No of } \\
\text { Obs }\end{array}$} & \multirow{2}{*}{$\begin{array}{l}\text { Cross } \\
\text { Sectio } \\
\text { nal } \\
\text { Units }\end{array}$} & \multirow[t]{2}{*}{ P-value } \\
\hline & $\begin{array}{l}\text { Period } 1 \\
\text { (prior to } \\
1979 \text { ) }\end{array}$ & $\begin{array}{lr}\text { Period } 2 \\
(1979 \text { to } \\
1992) & \\
\end{array}$ & $\begin{array}{l}\text { Period } 3 \\
\text { (1993 } \\
\text { onwards) }\end{array}$ & $\begin{array}{l}\text { Period } 1 \\
\text { (prior to } \\
1979 \text { ) }\end{array}$ & $\begin{array}{l}\text { Period } 2 \\
(1979 \text { to } \\
1992)\end{array}$ & $\begin{array}{l}\text { Period } 3 \\
\text { (1993 } \\
\text { onwards) }\end{array}$ & & & & \\
\hline NSDP (all Sectors) & 0.038 & 0.036 & 0.055 & 6.99 & 6.94 & 11.90 & 0.110 & 78 & 31 & 0.0124 \\
\hline All Primary & 0.023 & 0.023 & 0.018 & 3.71 & 3.91 & 3.48 & 0.006 & 78 & 31 & 0.7869 \\
\hline $\mathrm{Mfg}$ & 0.060 & 0.063 & 0.053 & 7.53 & 8.36 & 7.85 & 0.014 & 78 & 31 & 0.5939 \\
\hline Mfg Registered & 0.081 & 0.077 & 0.053 & 6.05 & 6.13 & 4.76 & 0.042 & 75 & 30 & 0.2149 \\
\hline Mfg Unregistered & 0.042 & 0.042 & 0.040 & 4.53 & 4.86 & 5.19 & 0.003 & 78 & 31 & 0.9871 \\
\hline All Tertiary & 0.045 & 0.051 & 0.069 & 7.44 & 9.08 & 13.68 & 0.128 & 78 & 31 & 0.0058 \\
\hline Banking, Insurance etc & 0.100 & 0.125 & 0.107 & 16.07 & 21.12 & 20.14 & 0.102 & 78 & 31 & 0.0180 \\
\hline Construction & 0.050 & 0.040 & 0.088 & 5.28 & 4.51 & 10.93 & 0.191 & 78 & 31 & 0.0004 \\
\hline Agriculture & 0.026 & 0.032 & 0.026 & 5.60 & 7.16 & 6.42 & 0.016 & 78 & 31 & 0.5537 \\
\hline Trade Hotels and Restaurants & 0.055 & 0.052 & 0.069 & 7.85 & 7.91 & 11.79 & 0.058 & 78 & 31 & 0.1045 \\
\hline Other Services & 0.036 & 0.061 & 0.058 & 7.14 & 12.72 & 13.45 & 0.162 & 78 & 31 & 0.0013 \\
\hline Public Administration etc & 0.068 & 0.073 & 0.062 & 13.30 & 15.17 & 14.38 & 0.037 & 78 & 31 & 0.2475 \\
\hline Transport, Storage etc & 0.057 & 0.081 & 0.099 & 7.83 & 11.92 & 16.27 & 0.212 & 78 & 31 & 0.0001 \\
\hline
\end{tabular}




\begin{tabular}{|c|c|c|c|c|c|c|c|c|c|c|c|c|c|}
\hline & & SDP & & & Mfg & & & SDP Agricult & & & SDP Tertiary & ector & \\
\hline & Value & Coefficient & T-value & Imp.\# & Coefficient & T-value & Imp.\# & Coefficient & T-value & Imp.\# & Coefficient & T-value & Imp.\# \\
\hline Constant & & 0.0548362 & 13.32 & & 0.0567748 & 6.584 & & 0.0306104 & 1 & 11 & 0.0703398 & 21.26 & \\
\hline $\begin{array}{l}\text { Prior period per } \\
\text { capita SDP }\end{array}$ & 225.078 & 0.0000683 & 3.561 & $2.80 \%$ & 0.0000647 & 1.611 & $2.56 \%$ & 0.0000041 & 0.118 & $0.30 \%$ & 0.0000578 & 3.757 & $1.85 \%$ \\
\hline $\begin{array}{l}1979 \text { percapita sdp } \\
\text { * Period } 3 \text { dummy }\end{array}$ & 171.868 & -0.0001266 & -4.106 & $\begin{array}{l}- \\
3.97 \%\end{array}$ & -0.0000656 & -1.016 & - & -0.0000390 & -7012 & $-2.19 \%$ & -0.0001485 & -6 & $-3.63 \%$ \\
\hline $\begin{array}{l}1992 \text { percapita sdp } \\
\text { * Period } 4 \text { dummy }\end{array}$ & 195.366 & -0.0001970 & -8.385 & $\begin{array}{l}- \\
7.02 \%\end{array}$ & -0.0000469 & -0.956 & $\begin{array}{l}- \\
1.62 \%\end{array}$ & -0.0000255 & -6014 & $-1.63 \%$ & -0.0002051 & -10.89 & $-5.70 \%$ \\
\hline $\begin{array}{l}2003 \text { percapita sdp } \\
\text { * Period } 5 \text { dummy }\end{array}$ & 231.841 & -0.0001205 & -5.492 & $\begin{array}{l}- \\
5.09 \%\end{array}$ & -0.0000959 & -2.091 & $\begin{array}{l}- \\
3.92 \%\end{array}$ & -0.0000471 & -1.19 & $-3.57 \%$ & -0.0000873 & -4.958 & $-2.88 \%$ \\
\hline Rsq & & 0.075396 & & & 0.004956 & & & 0.002233 & & & 0.12125 & & \\
\hline No of Obs & & 955 & & & 952 & & & 952 & & & 952 & & \\
\hline $\begin{array}{l}\text { No of Cross } \\
\text { Sectional Units }\end{array}$ & & 31 & & & 31 & & & 31 & & & 31 & & \\
\hline P-value & & $2.48 \mathrm{E}-15$ & & & 0.318396 & & & 0.713913 & & & $1.54 \mathrm{E}-25$ & & \\
\hline Total Impact & & -0.0003758 & & & -0.0001437 & & & -0.0001075 & & & -0.0003831 & & \\
\hline
\end{tabular}


Table 10: Convergence of Average Growth Rates Across States - Sector Wise and For Overall SDP

Dependent variable (Period average Growth Rate)

\begin{tabular}{|l|} 
\\
\hline Constant \\
\hline Prior to period per capita sdp \\
\hline 1979 per capita income*Period 2 dummy \\
\hline
\end{tabular}

1979 per capita income*Period 2 dummy

1992 per capita income *Period 3 dummy

Prior period per capita mfg value added

1979 per capita mfg value added *Period 2 dummy

1992 per capita mfg value added *Period 3 dummy

Prior period per capita Agr value added

1979 per capita Agr value added * Period 2 dummy

1992 per capita Agr value added * Period 3 dummy

Prior period per capita sdp in tertiary sector

1979 per capita tertiary value added * Period 2 dummy

1992 per capita tertiary value added * Period 3 dummy

No of Obs

No of Cross Sectional Units

P-value

--Continued--'

\begin{tabular}{|l|l|}
\hline & \\
\hline Mean \\
Values \\
\\
\\
\hline \\
\hline 196.6 \\
\hline 195.8 \\
\hline 218.9 \\
\hline 16.2 \\
\hline 14.4 \\
\hline 22.1 \\
\hline 40.8 \\
\hline 40.0 \\
\hline 41.9 \\
\hline 81.3 \\
\hline 81.8 \\
\hline 89.3 \\
\hline \\
\hline
\end{tabular}

\begin{tabular}{|c|c|c|}
\hline \multicolumn{3}{|l|}{ SDP } \\
\hline Coeff. & $\begin{array}{l}\mathrm{t} \\
\text { ratio }\end{array}$ & \\
\hline 0.0574 & 13.35 & \\
\hline-0.0001 & -2.52 & -2.2 \\
\hline-0.0001 & -3.05 & -2.8 \\
\hline 0.0000 & 1.58 & 1.5 \\
\hline & & \\
\hline & & \\
\hline & & \\
\hline & & \\
\hline & & \\
\hline & & \\
\hline & & \\
\hline 0.41 & & \\
\hline 69 & & \\
\hline 25 & & \\
\hline 0.00 & & \\
\hline & & \\
\hline
\end{tabular}

SDP Mfg (1)

\section{\begin{tabular}{|l|l|}
\hline SDP Mfg (2) & SDP Agriculture (1) \\
\hline
\end{tabular}}

\begin{tabular}{|c|c|c|c|c|c|c|c|c|}
\hline Coeff. & t ratio & $\begin{array}{l}\% \text { Eff. } \\
\text { on Gr } \\
\text { rt of } \\
10 \% \\
\text { rise }\end{array}$ & Coeff. & $\begin{array}{l}\mathrm{t} \\
\text { ratio }\end{array}$ & $\begin{array}{l}\% \text { Eff. } \\
\text { on Gr } \\
r t \text { of } \\
10 \% \\
\text { rise }\end{array}$ & Coeff. & $\begin{array}{l}\mathrm{t} \\
\text { ratio }\end{array}$ & $\begin{array}{l}\% \text { Eff. } \\
\text { on Gr } \\
\text { rt of } \\
10 \% \\
\text { rise }\end{array}$ \\
\hline
\end{tabular}

\begin{tabular}{|llllllllll|l|l|}
\hline 0.0514 & 6.46 & & 0.0543 & 5.72 & & 0.0369 & 4.94 & \\
\hline & & & & 0.0000 & -0.57 & -0.73 & & & \\
\hline 0.0006 & 0.76 & 1.92 & 0.0007 & 0.82 & 1.96 & & & \\
\hline-0.0001 & 0.15 & 0.34 & 0.0001 & 0.19 & 0.39 & & & \\
\hline & -0.43 & -1.36 & -0.0003 & -0.41 & -1.22 & & & \\
\hline & & & & & & -0.0003 & -0.01 & -2.99 \\
\hline & & & & & & & 0.0002 & 0.97 & 1.65 \\
\hline & & & & & & 0.0000 & 0.01 & 0.02 \\
\hline & & & & & & & & \\
\hline & & & & & & & & \\
\hline & & & & 0.03 & & & 0.05 & & \\
\hline 69 & & & 69 & & & 69 & & \\
\hline 25 & & & 25 & & & 25 & & \\
\hline & & & & & & & & & & & \\
\hline
\end{tabular}


(Table 10 Cont.)

\begin{tabular}{|c|c|c|c|c|c|c|c|c|c|c|}
\hline \multirow[b]{2}{*}{ Constant } & \multirow{2}{*}{$\begin{array}{l}\text { Mean } \\
\text { Values }\end{array}$} & \multicolumn{3}{|c|}{ SDP Agriculture (2) } & \multicolumn{3}{|c|}{ SDP Tertiary Sector (1) } & \multicolumn{3}{|c|}{ SDP Tertiary Sector (2) } \\
\hline & & 0.0450 & 5.74 & & 0.0630 & 19.31 & & 0.0606 & 12.94 & \\
\hline Prior to period per capita $s d p$ & 196.6 & 0.0000 & -2.57 & -2.07 & & & & 0.0000 & 0.73 & 0.83 \\
\hline 1979 per capita income*Period 2 dummy & 195.8 & & & & & & & & & \\
\hline 1992 per capita income *Period 3 dummy & 218.9 & & & & & & & & & \\
\hline Prior period per capita mfg value added & 16.2 & & & & & & & & & \\
\hline 1979 per capita mfg value added *Period 2 dummy & 14.4 & & & & & & & & & \\
\hline 1992 per capita mfg value added *Period 3 dummy & 22.1 & & & & & & & & & \\
\hline Prior period per capita Agr value added & 40.8 & -0.0003 & -1.42 & -2.48 & & & & & & \\
\hline 1979 per capita Agr value added * Period 2 dummy & 40.0 & 0.0002 & 1.17 & 1.58 & & & & & & \\
\hline 1992 per capita Agr value added * Period 3 dummy & 41.9 & 0.0001 & 0.47 & 0.64 & & & & & & \\
\hline Prior period per capita sdp in tertiary sector & 81.3 & & & & -0.0001 & -2.55 & -1.10 & -0.0001 & -2.28 & -1.50 \\
\hline 1979 per capita tertiary value added * Period 2 dummy & 81.8 & & & & -0.0002 & -4.13 & -2.28 & -0.0002 & -4.13 & -2.39 \\
\hline 1992 per capita tertiary value added * Period 3 dummy & 89.3 & & & & 0.0001 & 2.45 & 1.77 & 0.0001 & 2.02 & 1.63 \\
\hline Rsq & & 0.14 & & & 0.56 & & & 0.56 & & \\
\hline No of Obs & & 69 & & & 69 & & & 69 & & \\
\hline No of Cross Sectional Units & & 25 & & & 25 & & & 25 & & \\
\hline P-value & & 0.05 & & & 0.00 & & & 0.00 & & \\
\hline
\end{tabular}




\begin{tabular}{|l|l|l|l|l|l|l|}
\hline \multicolumn{7}{|l|}{ Table 11: Regression Results: Share of Agricultural GDP on "Structural Variables" } \\
\hline & & Coefficient & Std.Error & t-ratio & P-value & Sign. \\
\hline Constant & $\hat{\alpha}$ & 1.4239 & 0.0681 & 20.9 & $1.40 \mathrm{E}-77$ & $* * *$ \\
\hline Population Density & $\hat{\beta}_{1}$ & -0.0013 & 0.0002 & -5.341 & $1.21 \mathrm{E}-07$ & $* * *$ \\
\hline $\ln ($ Per Capita Income) & $\hat{\beta}_{2}$ & -0.1225 & 0.0071 & -17.36 & $1.92 \mathrm{E}-57$ & $* * *$ \\
\hline Rain & $\hat{\beta}_{3}$ & 0.0093 & 0.0030 & 3.14 & 0.0018 & $* * *$ \\
\hline R-squared & & 0.3710 & Adjusted R-squared & 0.368646 & \\
\hline $\mathrm{F}(3,792)$ & & 155.7329 & P-value(F) & $2.48 \mathrm{E}-79$ & \\
\hline
\end{tabular}

Table 12: Regression Results of Share of Agriculture in NSDP (Structural) with Dummies for Some States

\begin{tabular}{|l|l|l|l|l|l|l|}
\hline & & Coefficient & Std. Error & t-Value & p- value & Sign. \\
\hline Constant & $\hat{\alpha}$ & 1.3872 & 0.0657 & 21.1100 & $1.10 \mathrm{E}-78$ & $* * *$ \\
\hline Population Density & $\hat{\beta}_{1}$ & -0.0014 & 0.0002 & -6.3460 & $3.73 \mathrm{E}-10$ & $* * *$ \\
\hline Log of Per Capita Income & $\hat{\beta}_{2}$ & -0.1177 & 0.0068 & -17.3600 & $2.29 \mathrm{E}-57$ & $* * *$ \\
\hline Rainfall & $\hat{\beta}_{3}$ & 0.0100 & 0.0028 & 3.5550 & 0.0004 & $* * *$ \\
\hline Gujarat Dummy & $D(G J)$ & -0.0163 & 0.0143 & -1.1440 & 0.253 & \\
\hline Andhra Pradesh Dummy & $D(A P)$ & 0.0482 & 0.0144 & 3.3490 & 0.0008 & $* * *$ \\
\hline Karnataka Dummy & $D(K A)$ & -0.0031 & 0.0144 & -0.2137 & 0.8308 & \\
\hline Maharashtra Dummy & $D(M H)$ & -0.1121 & 0.0143 & -7.8300 & $1.57 \mathrm{E}-14$ & $* * *$ \\
\hline Tamil Nadu Dummy & $D(T N)$ & -0.0866 & 0.0143 & -6.0640 & $2.06 \mathrm{E}-09$ & $* * *$ \\
\hline West Bengal Dummy & $D(W B)$ & -0.0212 & 0.0147 & -1.4470 & 0.1483 & \\
\hline R-squared & & 0.4492 & Adjusted R-squared & 0.442848 & \\
\hline F(9, 786) & & 71.2112 & P-value(F) & & $1.09 \mathrm{E}-95$ & \\
\hline
\end{tabular}

Table 13: Regression Results of Share of Agriculture in NSDP (Structural + Irrigation)

\begin{tabular}{|l|l|l|l|l|l|l|}
\hline & & Coefficient & Std. Error & t-Value & p-value & Sign. \\
\hline Constant & $\hat{\alpha}$ & 1.5032 & 0.0853 & 17.6300 & $2.66 \mathrm{E}-54$ & $* * *$ \\
\hline Lopulation Density & $\hat{\beta}_{1}$ & -0.0015 & 0.0002 & -6.4990 & $1.99 \mathrm{E}-10$ & $* * *$ \\
\hline Rainfall & $\hat{\beta}_{2}$ & -0.1332 & 0.0089 & -15.0000 & $3.80 \mathrm{E}-42$ & $* * *$ \\
\hline Irrigation Intensity & $\hat{\beta}_{3}$ & 0.0023 & 0.0027 & 0.8606 & 0.3899 & \\
\hline Irrigation Proportion by Wells & $\hat{\beta}_{4}$ & 0.2908 & 0.0167 & 17.3700 & $4.24 \mathrm{E}-53$ & $* * *$ \\
\hline Irrigation Proportion by Canals & $\hat{\beta}_{5}$ & -0.0431 & 0.0145 & -2.9740 & 0.0031 & $* * *$ \\
\hline R-squared & $\hat{\beta}_{6}$ & 0.0058 & 0.0136 & 0.4281 & 0.6687 & \\
\hline $\mathrm{F}(6,493)$ & & 0.5945 & Adjusted R-squared & 0.589597 & \\
\hline
\end{tabular}




\begin{tabular}{l} 
Table 14: Regression Results of Share of Agriculture in NSDP (Structural + Irrigation) with Dummies \\
for Some States \\
\hline
\end{tabular}

\begin{tabular}{|l|l|l|l|l|l|}
\hline Table 15: Regression of the Residuals of Eq 7 on Irrigation Related Variables and Some State Dummies \\
\hline Constant & 0.0097 & 0.0086 & 1.1320 & 0.2587 & \\
\hline Irrigation Intensity & 0.2420 & 0.0112 & 21.6100 & 0.0000 & $* * *$ \\
\hline Irrigation Prop Canals & 0.0288 & 0.0114 & 2.5250 & 0.0120 & $* *$ \\
\hline Irrigation Prop Wells & -0.0357 & 0.0143 & -2.4910 & 0.0132 & $* *$ \\
\hline Gujarat Dummy & -0.0213 & 0.0096 & -2.2210 & 0.0270 & $* *$ \\
\hline Maharashtra Dummy & -0.1192 & 0.0083 & -14.3500 & 0.0000 & $* * *$ \\
\hline Tamil Nadu Dummy & -0.1314 & 0.0070 & -18.7900 & 0.0000 & $* * *$ \\
\hline West Bengal Dummy & -0.0634 & 0.0097 & -6.5530 & 0.0000 & $* * *$ \\
\hline R-squared & 0.8377 & Adjusted R-squared & 0.834094 & \\
\hline $\mathrm{F}(7,318)$ & 234.4202 & P-value(F) & $1.80 \mathrm{E}-121$ & \\
\hline
\end{tabular}




\begin{tabular}{|c|c|c|c|c|c|c|c|c|c|c|c|c|c|}
\hline \multirow[b]{2}{*}{ State Code } & \multirow[b]{2}{*}{ State } & \multirow{2}{*}{$\begin{array}{l}1971-79 \\
\text { NSDP1971 }\end{array}$} & \multirow[b]{2}{*}{ Structural } & \multirow[b]{2}{*}{ Residual } & \multicolumn{2}{|l|}{ 1979-1993 } & \multirow[b]{2}{*}{ Residual } & \multicolumn{2}{|l|}{$1993-2003$} & \multirow[b]{2}{*}{ Residual } & \multicolumn{2}{|l|}{$2003-2010$} & \multirow[b]{2}{*}{ Residual } \\
\hline & & & & & NSDP1979 & Structural & & NSDP1993 & Structural & & NSDP2001 & Structural & \\
\hline 1 & AN & & & & & & & -81848 & -1.839 & 2.839 & $1.05 \mathrm{E}+05$ & 1.115 & -0.115 \\
\hline 2 & AP & $1.18 \mathrm{E}+06$ & 0.965 & 0.035 & $4.36 \mathrm{E}+06$ & 0.974 & 0.026 & $7.51 E+06$ & 0.993 & 0.007 & $1.29 \mathrm{E}+07$ & 0.964 & 0.036 \\
\hline 3 & $A R$ & 35483 & 0.178 & 0.822 & $2.13 \mathrm{E}+05$ & 0.105 & 0.895 & $\begin{array}{l}-74968 \\
\end{array}$ & -1.732 & 2.732 & $2.04 \mathrm{E}+05$ & 0.750 & 0.250 \\
\hline 4 & AS & $4.49 E+05$ & 0.994 & 0.006 & $1.31 \mathrm{E}+06$ & 1.151 & -0.151 & $9.68 \mathrm{E}+05$ & 2.527 & -1.527 & $1.84 \mathrm{E}+06$ & 1.496 & -0.496 \\
\hline 5 & $\mathrm{BI}$ & $5.24 \mathrm{E}+05$ & 1.177 & -0.177 & $1.31 \mathrm{E}+06$ & 1.486 & -0.486 & $2.50 \mathrm{E}+06$ & 1.172 & -0.172 & $4.55 \mathrm{E}+06$ & 0.941 & 0.059 \\
\hline 6 & $\mathrm{CH}$ & & & & & & & & & & $6.40 \mathrm{E}+05$ & 0.842 & 0.158 \\
\hline 7 & CT & & & & & & & & & & $3.04 \mathrm{E}+06$ & 0.729 & 0.271 \\
\hline 8 & $\mathrm{DE}$ & $4.51 \mathrm{E}+05$ & 0.875 & 0.125 & $2.50 \mathrm{E}+06$ & 0.714 & 0.286 & $3.89 \mathrm{E}+06$ & 1.036 & -0.036 & $7.85 \mathrm{E}+06$ & 0.936 & 0.064 \\
\hline 9 & GD & $1.52 \mathrm{E}+05$ & 0.705 & 0.295 & $2.44 \mathrm{E}+05$ & 1.981 & -0.981 & $3.04 \mathrm{E}+05$ & 1.888 & -0.888 & $7.22 \mathrm{E}+05$ & 1.126 & -0.126 \\
\hline 10 & GJ & $1.18 \mathrm{E}+06$ & 1.013 & -0.013 & $3.52 \mathrm{E}+06$ & 1.404 & -0.404 & $5.15 \mathrm{E}+06$ & 1.344 & -0.344 & $1.46 \mathrm{E}+07$ & 0.733 & 0.267 \\
\hline 11 & $\mathrm{HP}$ & $1.67 \mathrm{E}+05$ & 0.659 & 0.341 & $3.14 \mathrm{E}+05$ & 1.331 & -0.331 & $8.21 \mathrm{E}+05$ & 0.811 & 0.189 & $1.05 \mathrm{E}+06$ & 1.263 & -0.262 \\
\hline 12 & $\mathrm{HR}$ & $6.46 \mathrm{E}+05$ & 0.602 & 0.398 & $1.99 \mathrm{E}+06$ & 0.796 & 0.204 & $3.14 \mathrm{E}+06$ & 0.921 & 0.079 & $6.54 \mathrm{E}+06$ & 0.825 & 0.175 \\
\hline 13 & $\mathrm{JH}$ & & & & & & & & & & $3.21 \mathrm{E}+06$ & 0.841 & 0.159 \\
\hline 14 & $\mathrm{JK}$ & $5.40 \mathrm{E}+05$ & 0.318 & 0.682 & $-1.26 \mathrm{E}+05$ & -4.832 & 5.832 & $6.75 \mathrm{E}+05$ & 1.422 & -0.422 & $1.00 \mathrm{E}+06$ & 1.368 & -0.368 \\
\hline 15 & KA & $8.23 E+05$ & 1.026 & -0.025 & $2.87 \mathrm{E}+06$ & 1.166 & -0.166 & $6.10 \mathrm{E}+06$ & 0.888 & 0.112 & $8.74 E+06$ & 1.161 & -0.161 \\
\hline 16 & KE & $3.18 \mathrm{E}+06$ & 1.292 & -0.292 & $-1.22 \mathrm{E}+07$ & -2.199 & 3.199 & $3.91 \mathrm{E}+06$ & 1.135 & -0.135 & $6.72 \mathrm{E}+06$ & 1.080 & -0.080 \\
\hline 17 & MG & & & & & & & $2.33 \mathrm{E}+05$ & 0.910 & 0.090 & $2.58 \mathrm{E}+05$ & 1.350 & -0.350 \\
\hline 18 & $\mathrm{MH}$ & $3.05 \mathrm{E}+06$ & 0.787 & 0.213 & $9.07 \mathrm{E}+06$ & 1.057 & -0.057 & $1.20 \mathrm{E}+07$ & 1.481 & -0.481 & $3.19 \mathrm{E}+07$ & 0.824 & 0.176 \\
\hline 19 & $\mathrm{MN}$ & & & & & & & & & & & & \\
\hline 20 & MP & $4.93 \mathrm{E}+05$ & 1.726 & -0.726 & $2.05 \mathrm{E}+06$ & 1.288 & -0.288 & $2.55 \mathrm{E}+06$ & 1.716 & -0.716 & $5.23 \mathrm{E}+06$ & 1.160 & -0.159 \\
\hline 21 & $\mathrm{MZ}$ & & & & & & & & & & $1.66 \mathrm{E}+05$ & 0.903 & 0.097 \\
\hline 22 & NG & & & & & & & $1.65 \mathrm{E}+05$ & 1.171 & -0.171 & & & \\
\hline 23 & OR & $5.66 \mathrm{E}+05$ & 1.051 & -0.051 & $8.47 E+05$ & 2.401 & -1.401 & $1.53 \mathrm{E}+06$ & 1.695 & -0.695 & $4.45 \mathrm{E}+06$ & 0.823 & 0.177 \\
\hline 24 & PD & & & & & & & & & & & & \\
\hline 25 & PN & $9.79 \mathrm{E}+05$ & 0.587 & 0.413 & $2.34 \mathrm{E}+06$ & 1.040 & -0.040 & $2.34 \mathrm{E}+06$ & 1.542 & -0.542 & $4.67 \mathrm{E}+06$ & 1.092 & -0.092 \\
\hline 26 & RJ & $5.62 \mathrm{E}+05$ & 1.413 & -0.413 & $3.08 \mathrm{E}+06$ & 0.842 & 0.158 & $2.88 \mathrm{E}+06$ & 1.536 & -0.536 & $6.58 \mathrm{E}+06$ & 1.003 & -0.003 \\
\hline 27 & SK & & & & & & & & & & 87787 & 1.075 & -0.075 \\
\hline 28 & $\mathrm{TN}$ & $1.43 \mathrm{E}+06$ & 1.285 & -0.285 & $3.99 \mathrm{E}+06$ & 1.509 & -0.509 & $7.11 \mathrm{E}+06$ & 1.296 & -0.296 & $1.34 \mathrm{E}+07$ & 1.120 & -0.120 \\
\hline 29 & TR & & & & $1.62 \mathrm{E}+05$ & 0.790 & 0.210 & $3.45 \mathrm{E}+05$ & 0.741 & 0.259 & $4.81 \mathrm{E}+05$ & 1.008 & -0.008 \\
\hline 30 & UP & $1.72 \mathrm{E}+06$ & 1.194 & -0.194 & $6.11 \mathrm{E}+06$ & 1.123 & -0.123 & $6.07 \mathrm{E}+06$ & 1.854 & -0.854 & $1.06 \mathrm{E}+07$ & 1.344 & -0.344 \\
\hline 31 & UT & & & & & & & & & & $2.15 \mathrm{E}+06$ & 0.626 & 0.374 \\
\hline \multirow[t]{3}{*}{32} & WB & $1.11 \mathrm{E}+06$ & 1.355 & -0.355 & $3.87 \mathrm{E}+06$ & 1.304 & -0.304 & $7.60 \mathrm{E}+06$ & 0.966 & 0.034 & $1.00 \mathrm{E}+07$ & 1.232 & -0.232 \\
\hline & \multicolumn{2}{|c|}{ Average } & 0.960 & 0.040 & & 0.735 & 0.265 & & 1.061 & -0.061 & & 1.025 & -0.025 \\
\hline & \multicolumn{2}{|c|}{ Average excl KE and JK } & 0.977 & 0.023 & & 1.182 & -0.182 & & 1.042 & -0.042 & & 1.010 & -0.010 \\
\hline
\end{tabular}


Table 17: Regression of Growth Rate of Registered Mfg. on Growth Rate of Agriculture, Tertiary Sector and Electricity Sales

\begin{tabular}{|l|l|l|l|l|l|l|}
\hline $\begin{array}{l}\text { Variable (Growth } \\
\text { Rate) }\end{array}$ & In. Eq. & Coefficient & Std. Error & t-Value & p- value & Sign. \\
\hline Constant & $\hat{\theta}$ & 0.0247 & 0.0153 & 1.613 & 0.1071 & \\
\hline Electricity Sales & $\hat{\beta}_{3}$ & 0.2395 & 0.0905 & 2.645 & 0.0084 & $* * *$ \\
\hline Agriculture (-1) & $\hat{\beta}_{1}$ & 0.2137 & 0.0719 & 2.970 & 0.0031 & $* * *$ \\
\hline Tertiary Sector & $\hat{\beta}_{2}$ & 0.4989 & 0.1692 & 2.949 & 0.0033 & $* * *$ \\
\hline $\mathrm{R}$-squared & & 0.0358 & \multicolumn{2}{|l|}{ Adjusted R-squared } & 0.0315 & \\
\hline $\mathrm{F}(3,680)$ & & 8.4111 & \multicolumn{2}{l|}{ P-value(F) } & 0.0000 & \\
\hline
\end{tabular}

Table 18: Regression of State Level NSDP Growth Rate on Certain Factors and Growth Rate of National Level GDP Growth Rate

\begin{tabular}{|l|l|l|l|l|l|l|}
\hline Variable (Growth Rate) & In Eq. & Coefficient & Std. Error & t-ratio & P-value & Sign. \\
\hline National Level GDP & $\hat{\alpha}_{z}$ & 0.294877 & 0.172151 & 1.713 & 0.0872 & $*$ \\
\hline Electricity Sales & $\hat{\beta}_{3}$ & 0.239893 & 0.089972 & 2.666 & 0.0079 & $* * *$ \\
\hline Agriculture (-1) & $\hat{\beta}_{1}$ & 0.208901 & 0.072274 & 2.89 & 0.004 & $* * *$ \\
\hline Tertiary Sector & $\hat{\beta}_{2}$ & 0.521204 & 0.157771 & 3.304 & 0.001 & $* * *$ \\
\hline R-squared & & 0.101081 & Adjusted R-squared & 0.097115 & \\
\hline $\mathrm{F}(4,680)$ & & 19.11599 & P-value(F) & $6.51 \mathrm{E}-15$ & \\
\hline
\end{tabular}




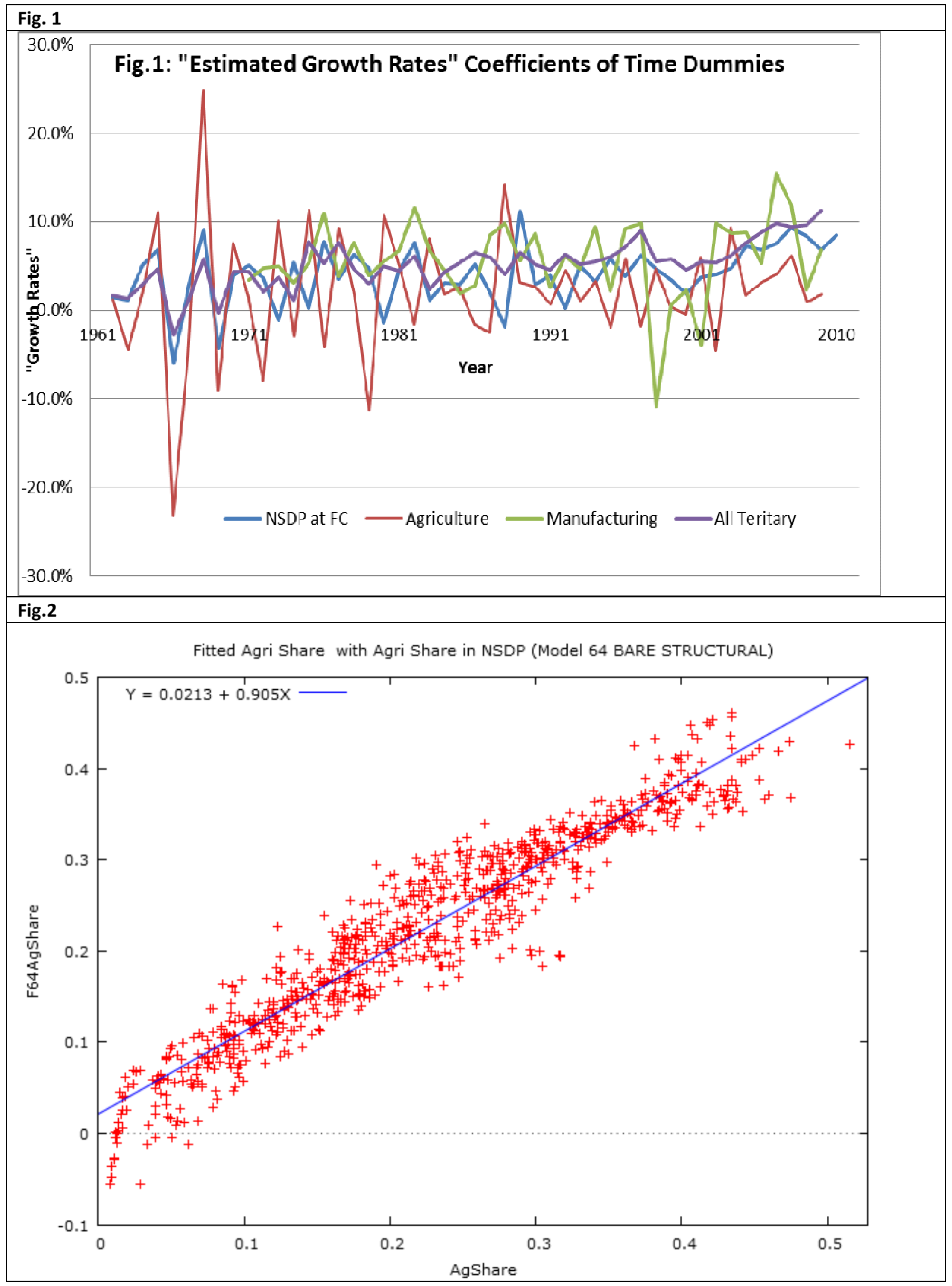


Fig. 3

Ratio of Agriculture Share in NSDP to Estimated Values (Structural Model)

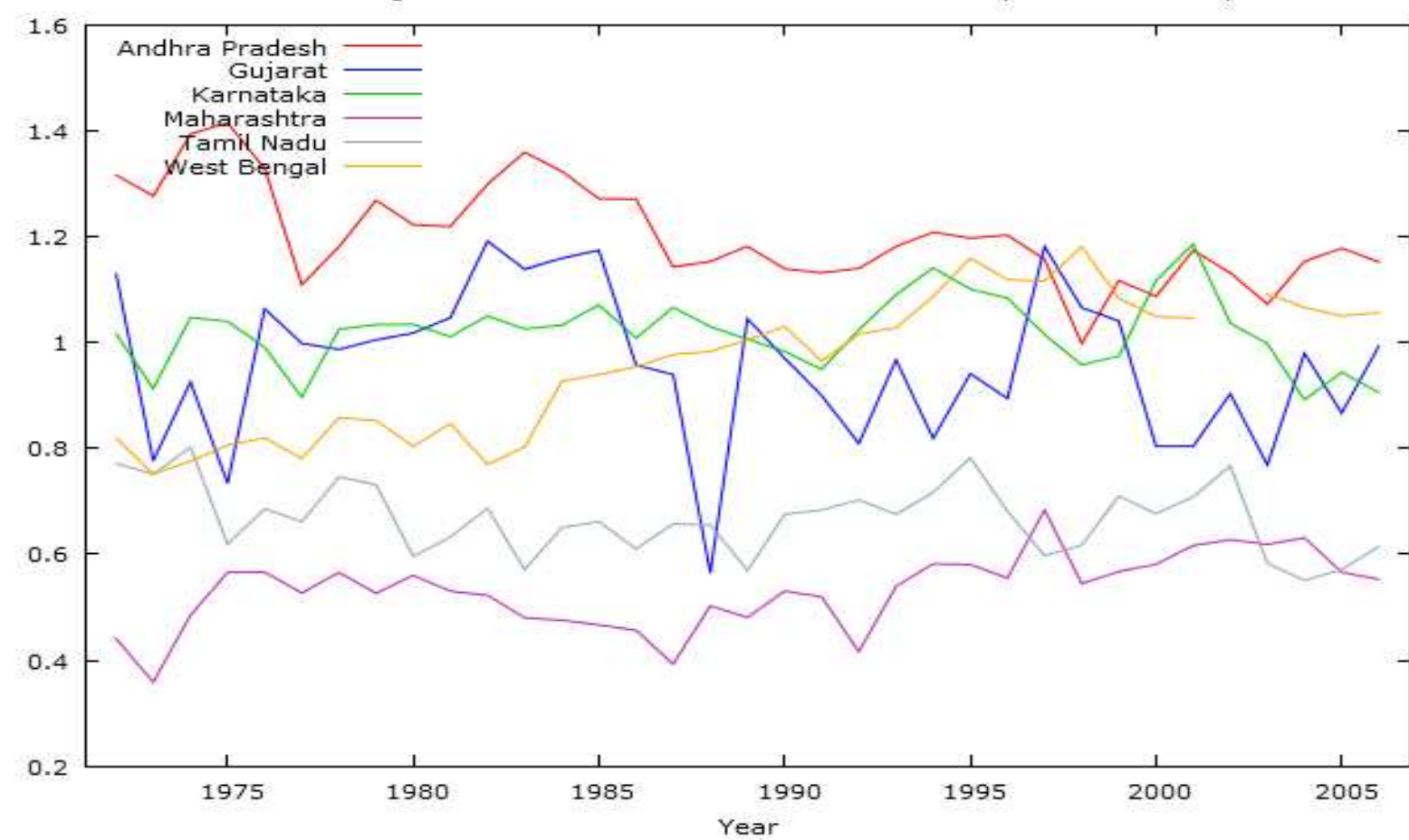

Fig. 4

Ratio of Agriculture Share in NSDP to Estimated Values (Structural Model)

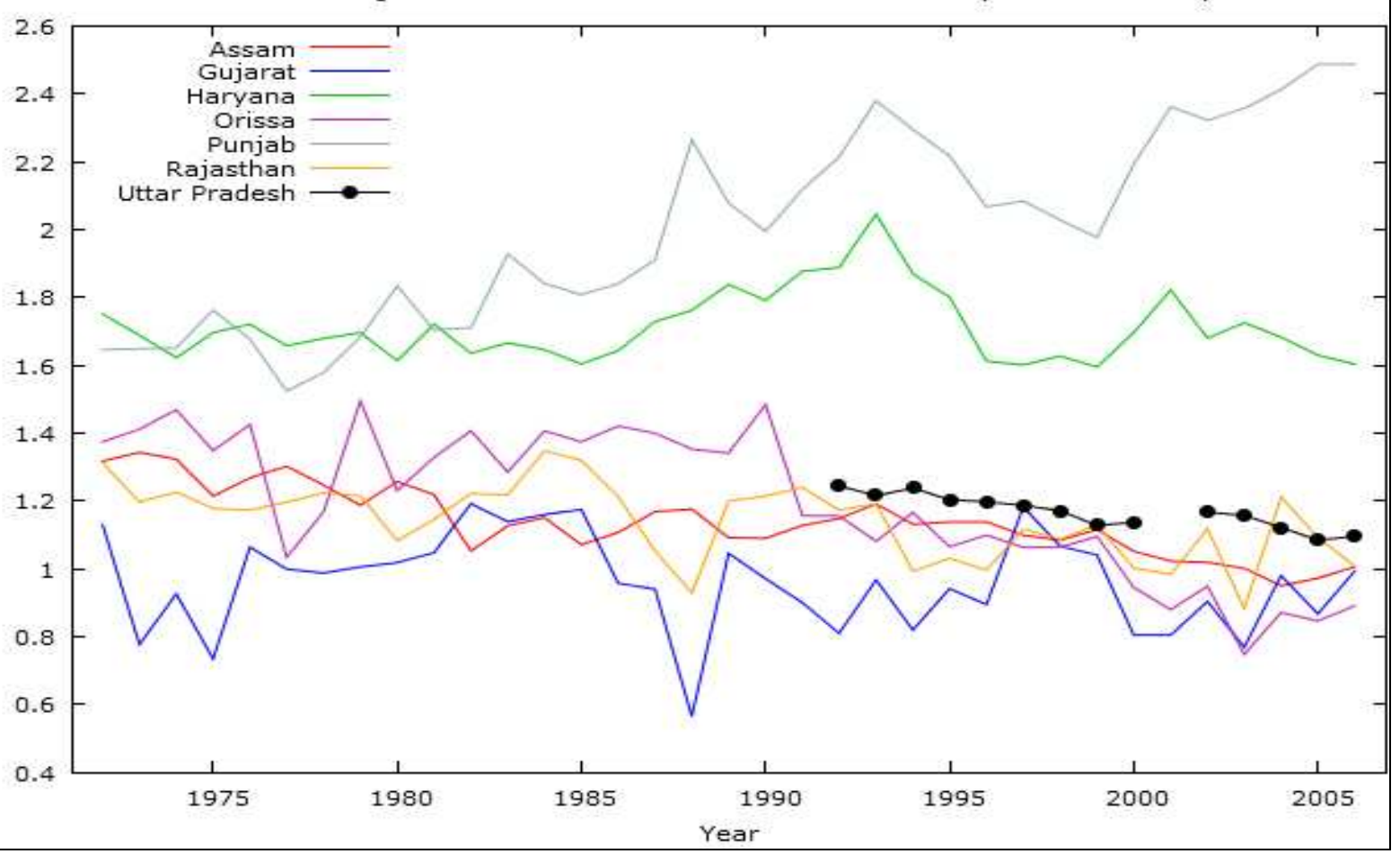




\begin{tabular}{|c|c|c|c|c|c|c|c|c|c|c|c|c|c|c|c|c|c|}
\hline \multicolumn{18}{|c|}{ Appendix Table1: Growth Rates (Trend compound as estimated through regressions on time of the log of values for each period). } \\
\hline StCode & Period & State & Y_1 & $\mathrm{Y}$ & P_1 & PA & SM & SMR & SMU & SC & T_1 & TB & $\mathrm{TH}$ & $\mathrm{TC}$ & TP & TR & TT \\
\hline 1 & 1 & AN & & & & & & & & & & & & & & & \\
\hline 1 & 2 & $\mathrm{AN}$ & 7.2 & 4.2 & 7.0 & 3.5 & 0.5 & -7.4 & 10.5 & 4.7 & 7.4 & 13.9 & 3.2 & 6.4 & 8.8 & 1.5 & 22.7 \\
\hline 1 & 3 & AN & -0.1 & 5.2 & -12.4 & -1.1 & -2.8 & -2.5 & 3.3 & 17.9 & 2.9 & 8.7 & 7.0 & 6.4 & 8.1 & 5.9 & -0.6 \\
\hline 2 & 1 & AP & 2.3 & 2.7 & 1.5 & 1.6 & 4.5 & 6.7 & 2.7 & 4.2 & 3.0 & 7.0 & 3.4 & 3.7 & 6.9 & & 5.4 \\
\hline 2 & 2 & AP & 4.9 & 5.7 & 2.0 & 2.6 & 8.8 & 10.7 & 5.9 & 4.2 & 7.2 & 13.7 & 8.6 & 7.4 & 5.8 & 5.9 & 4.8 \\
\hline 2 & 3 & AP & 6.4 & 6.5 & 4.2 & 3.7 & 5.3 & 5.2 & 5.6 & 8.5 & 7.7 & 11.0 & 7.4 & 6.9 & 5.5 & 6.8 & 11.0 \\
\hline 3 & 1 & AR & 3.1 & 7.1 & 2.1 & 7.1 & 15.1 & . & 15.1 & 6.2 & 10.3 & 24.7 & 19.4 & 7.3 & 11.0 & 3.2 & 10.9 \\
\hline 3 & 2 & AR & 6.6 & 8.3 & 6.1 & 9.3 & 7.9 & . & 7.9 & 6.8 & 9.5 & 17.9 & 9.5 & 11.9 & 6.7 & 4.8 & 14.5 \\
\hline 3 & 3 & AR & 0.7 & 5.9 & -4.7 & 3.8 & 3.4 & . & 3.4 & 8.2 & 7.3 & 10.1 & 3.1 & 6.6 & 9.3 & 6.5 & 10.1 \\
\hline 4 & 1 & AS & 3.2 & 3.1 & 3.0 & 2.4 & -2.9 & -5.8 & 0.5 & 5.9 & 4.2 & 8.7 & 2.7 & 3.0 & 11.8 & 7.0 & 5.7 \\
\hline 4 & 2 & AS & 3.8 & 3.9 & 3.2 & 2.7 & 5.5 & 6.8 & 2.1 & 3.8 & 4.3 & 13.7 & 4.0 & 2.9 & 7.2 & 2.3 & 4.8 \\
\hline 4 & 3 & AS & 3.3 & 3.4 & 1.3 & 1.2 & 3.0 & 2.1 & 3.8 & 2.9 & 5.0 & 10.1 & 3.9 & 6.8 & 6.2 & 3.3 & 3.3 \\
\hline 5 & 1 & $\mathrm{BI}$ & 3.0 & 3.2 & 1.7 & 1.7 & 4.2 & 4.0 & 4.8 & 8.4 & 4.3 & 8.5 & 8.8 & 4.4 & 0.5 & -0.9 & 3.5 \\
\hline 5 & 2 & $\mathrm{BI}$ & 3.9 & 4.4 & 2.8 & 2.4 & 7.7 & 12.1 & 3.8 & 6.1 & 4.6 & 10.8 & 4.5 & 5.9 & 7.4 & 1.8 & 2.8 \\
\hline 5 & 3 & $\mathrm{Bl}$ & 5.7 & 5.5 & 2.9 & 2.8 & 2.3 & -1.1 & 1.8 & 12.9 & 7.1 & 9.2 & 9.9 & 4.9 & 4.2 & 3.5 & 6.5 \\
\hline 6 & 1 & $\mathrm{CH}$ & & . & & . & &. & & . & . & . & . & . &. & . & . \\
\hline 6 & 2 & $\mathrm{CH}$ & & & & . & & & & & & & & & & & \\
\hline 6 & 3 & $\mathrm{CH}$ & 9.7 & 10.1 & -1.2 & . & 4.5 & $\begin{array}{l}-1.2 \\
\end{array}$ & 7.2 & 21.1 & 9.6 & 11.3 & 14.6 & 7.1 & 3.0 & 6.4 & 12.1 \\
\hline 7 & 1 & CT & & . & & . & & . & & . & . & . & &. & . & . & . \\
\hline 7 & 2 & $\mathrm{CT}$ &. & . & . &. & . &. &. &. & . & . &. &. & . & . & . \\
\hline 7 & 3 & CT & 4.8 & 5.2 & 3.2 & 0.5 & 7.3 & 8.1 & 3.9 & 9.9 & 6.4 & 11.5 & 6.7 & 5.6 & 6.4 & 2.8 & 9.8 \\
\hline 8 & 1 & $\mathrm{DE}$ & 4.4 & 6.0 & 0.3 & 0.1 & 5.2 & 6.1 & 4.4 & -3.0 & 6.0 & 12.8 & 5.9 & 4.1 & 8.2 & 4.8 & 6.5 \\
\hline 8 & 2 & $\mathrm{DE}$ & 7.1 & 7.6 & 5.0 & 3.8 & 8.8 & 9.1 & 8.7 & 7.0 & 7.1 & 1. & 7.4 & 6.0 & 7.8 & 5.6 & 7.6 \\
\hline 8 & 3 & $\mathrm{DE}$ & 7.9 & 8.1 & -3.0 & -3.2 & 5.2 & 4.5 & 5.5 & 7.0 & 8.5 & 10.9 & 7.2 & 6.9 & 5.3 & 1. & 9.3 \\
\hline 9 & 1 & GD & 7.0 & 6.3 & 3.5 & 1.4 & 17.7 & 40.1 & 5.9 & 7.1 & 6.0 & 18.3 & 6.5 & 4.3 & 13.2 & 4.8 & 2.3 \\
\hline 9 & 2 & GD & -0.6 & 6.0 & -2.3 & 1.9 & 8.3 & 13.3 & -8.9 & 4.0 & 6.7 & 10.9 & 3.4 & 5.4 & 7.5 & 3.7 & 12.2 \\
\hline 9 & 3 & GD & 5.9 & 6.7 & 2.0 & 1.0 & 9.3 & 9.4 & 9.2 & 6.0 & 6.0 & 11.2 & 2.3 & 4.9 & 3.7 & 5.9 & 9.6 \\
\hline 10 & 1 & GJ & 3.4 & 4.4 & 2.1 & 3.0 & 6.1 & 6.9 & 3.7 & 3.7 & 4.9 & 9.2 & 5.8 & 3.0 & 6.3 & 3.3 & 7.3 \\
\hline 10 & 2 & GJ & 3.5 & 4.4 & -0.1 & -0.8 & 6.9 & 7.1 & 6.2 & 4.3 & 5.8 & 12.6 & 5.3 & 5.1 & 6.1 & 3.1 & 9.7 \\
\hline 10 & 3 & GJ & 6.7 & 6.9 & 2.7 & 3.4 & 6.9 & 6.6 & 7.3 & 11.1 & 8.3 & 8.2 & 9.8 & 6.9 & 6.0 & 4.0 & 13.0 \\
\hline 11 & 1 & $\mathrm{HP}$ & 3.5 & 3.7 & 2.8 & 2.4 & 3.9 & 4.8 & 3.2 & 3.9 & 4.5 & 12.3 & 10.8 & 2.4 & 4.5 & 2.7 & 4.3 \\
\hline 11 & 2 & $\mathrm{HP}$ & 3.5 & 4.8 & 1.9 & 3.8 & 12.5 & 17.6 & 6.3 & 1.9 & 5.6 & 14.3 & 5.4 & 7.0 & 7.5 & 2.8 & 2.6 \\
\hline 11 & 3 & $\mathrm{HP}$ & 6.3 & 6.7 & 3.1 & 3.4 & 8.2 & 8.4 & 6.8 & 7.3 & 7.8 & 8.8 & 9.1 & 7.8 & 6.8 & 2.5 & 10.9 \\
\hline 12 & 1 & $\mathrm{HR}$ & 4.7 & 5.1 & 3.7 & 3.4 & 7.2 & 7.6 & 6.2 & 1.7 & 6.9 & 10.2 & 11.8 & 3.2 & 7.5 & 3.8 & 7.7 \\
\hline
\end{tabular}




\begin{tabular}{|c|c|c|c|c|c|c|c|c|c|c|c|c|c|c|c|c|c|}
\hline 12 & 2 & HR & 5.9 & 6.4 & 4.6 & 4.8 & 9.7 & 7.7 & 13.4 & 1.7 & 7.0 & 11.8 & 7.9 & 5.3 & 7.6 & 5.4 & 8.1 \\
\hline 12 & 3 & HR & 7.2 & 7.2 & 2.3 & 2.2 & 6.5 & 6.7 & 5.9 & 8.8 & 10.4 & 12.4 & 10.9 & 6.4 & 6.4 & 11.4 & 12.7 \\
\hline 13 & 1 & $\mathrm{JH}$ & . & . & . & . & . & . & . & . & . & . & . & . & . & . & . \\
\hline 13 & 2 & $\mathrm{JH}$ & . & . &. & . & &. & 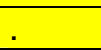 & . & . & . & & . & . & . & . \\
\hline 13 & 3 & JH & -0.5 & 5.5 & 3.3 & 5.7 & 7.1 & 7.6 & -16.1 & 3.4 & 1.2 & 14.0 & 7.2 & -7.3 & 8.3 & 6.3 & 6.3 \\
\hline 14 & 1 & JK & 5.8 & 4.3 & 6.4 & 3.1 & 5.9 & 15.3 & 2.6 & 5.5 & 4.3 & 13.1 & 5.0 & 2.9 & 5.6 & 2.4 & 6.1 \\
\hline 14 & 2 & JK & -0.6 & 2.4 & -6.0 & 1.8 & 6.0 & 6.8 & 5.5 & 3.7 & 4.2 & 8.1 & -1.5 & 4.2 & 12.1 & 1.9 & 8.4 \\
\hline 14 & 3 & JK & 4.3 & 4.6 & 2.9 & 3.2 & 6.1 & 3.6 & 5.1 & 3.8 & 5.8 & 8.3 & 2.5 & 6.8 & 5.4 & 2.3 & 14.4 \\
\hline 15 & 1 & $\mathrm{KA}$ & 2.8 & 4.0 & 0.8 & 2.5 & 7.5 & 8.8 & 6.0 & 2.7 & 4.2 & 8.7 & 4.4 & 1.6 & 8.5 & 3.8 & 5.9 \\
\hline 15 & 2 & $\mathrm{KA}$ & 4.3 & 4.9 & 1.2 & 2.6 & 7.4 & 9.1 & 3.7 & 3.2 & 6.3 & 12.0 & 7.1 & 5.9 & 7.8 & 4.0 & 5.7 \\
\hline 15 & 3 & $\mathrm{KA}$ & 6.7 & 6.6 & 2.2 & 2.0 & 6.0 & 5.8 & 6.1 & 9.6 & 8.8 & 10.8 & 8.7 & 6.8 & 5.5 & 8.3 & 13.3 \\
\hline 16 & 1 & $\mathrm{KE}$ & 2.5 & 1.6 & -0.1 & 0.1 & 2.3 & 3.4 & 1.2 & 2.5 & 2.8 & 8.8 & 0.4 & 2.9 & 5.6 & 2.9 & 4.7 \\
\hline 16 & 2 & $\mathrm{KE}$ & -10.7 & 3.1 & 0.1 & 2.8 & 3.5 & 4.3 & 2.0 & 2.7 & -13.9 & 11.5 & 2.5 & 1.6 & 8.1 & -21.9 & 8.0 \\
\hline 16 & 3 & $\mathrm{KE}$ & 6.0 & 6.1 & 1.2 & 1.0 & 4.0 & 3.3 & 4.8 & 6.3 & 7.6 & 12.6 & 6.1 & 5.8 & 7.4 & 7.8 & 12.3 \\
\hline 17 & 1 & $M G$ & & & & & & & & & & & & & & & \\
\hline 17 & 2 & MG & 4.9 & 5.2 & 1.9 & 1.4 & 7.5 & 10.4 & 6.1 & 2.5 & 6.9 & 14.0 & 6.6 & 7.4 & 8.0 & 3.8 & 12.4 \\
\hline 17 & 3 & MG & 6.0 & 6.3 & 5.5 & 5.4 & 14.6 & 21.9 & 1.7 & 8.0 & 5.8 & 9.7 & 7.8 & 6.1 & 5.1 & 2.0 & 8.5 \\
\hline 18 & 1 & $\mathrm{MH}$ & 4.2 & 5.7 & 3.3 & 7.1 & 6.3 & 6.8 & 4.4 & 1.3 & 4.6 & 5.7 & 6.3 & 2.1 & 7.9 & 3.2 & 4.8 \\
\hline 18 & 2 & $\overline{\mathrm{MH}}$ & 4.9 & 5.4 & 2.4 & 2.5 & 6.0 & 6.5 & 4.6 & 3.5 & 5.8 & 11.2 & 5.5 & 7.2 & 6.5 & 3.2 & 6.6 \\
\hline 18 & 3 & $\mathrm{MH}$ & 6.5 & 6.8 & 2.3 & 3.8 & 5.5 & 5.2 & 6.7 & 5.8 & 8.0 & 9.2 & 8.7 & 6.3 & 6.4 & 7.3 & 9.0 \\
\hline 19 & 1 & MN & . &. & . &. & . &. &. &. &. &. & . & . & . & . & . \\
\hline 19 & 2 & MN & . & . & . & . & . & . & . & . & . & . & . & . & . & . & . \\
\hline 19 & 3 & MN & . & . & 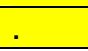 & . &. & . & . & . &. & . & . &. & . & . & . \\
\hline 20 & 1 & MP & 2.2 & 2.6 & 1.7 & 1.5 & 6.3 & 8.0 & 4.1 & 2.0 & 2.4 & 7.7 & 1.6 & 4.5 & 4.9 & 1.3 & 4.3 \\
\hline 20 & 2 & MP & 2.8 & 4.7 & 0.3 & 4.8 & 5.7 & 6.8 & 4.1 & -1.4 & 6.0 & 14.4 & 5.3 & 6.6 & 9.1 & 4.3 & 4.9 \\
\hline 20 & 3 & MP & 4.2 & 4.5 & 2.0 & 1.7 & 3.5 & 3.3 & 4.1 & 11.3 & 5.2 & 10.4 & 4.0 & 5.2 & 4.4 & 3.2 & 9.0 \\
\hline 21 & 1 & $\mathrm{MZ}$ & . & . & . & . & . & . & . & . & . & . & . & . & . & . & . \\
\hline 21 & 2 & $\mathrm{MZ}$ & . & . & . &. & . & . & . &. & . & . & . & . & . & . &. \\
\hline 21 & 3 & $\mathrm{MZ}$ & 6.8 & 7.0 & 5.0 & 6.5 & 4.0 & -0.5 & 4.4 & 11.3 & 6.9 & 13.3 & 5.6 & 3.1 & 8.1 & 8.5 & 11.6 \\
\hline 22 & 1 & $\mathrm{NG}$ & & & & & & & & & & & & & & & \\
\hline 22 & 2 & $\mathrm{NG}$ & 3.7 & 7.2 & 5.0 & 3.0 & 1.5 & -1.3 & 2.0 & 13.5 & 3.6 & 16.4 & 4.5 & 8.7 & 0.9 & 1.2 & 8.8 \\
\hline 22 & 3 & $\mathrm{NG}$ & 5.5 & 6.9 & 9.6 & 11.1 & -8.1 & -3.5 & -8.9 & 9.6 & 5.6 & 9.4 & 6.0 & 6.6 & 4.2 & 6.0 & 4.9 \\
\hline 23 & 1 & OR & 2.8 & 3.1 & 1.7 & 2.4 & 6.6 & 8.5 & 2.6 & 4.4 & 3.6 & 8.8 & 2.1 & 3.4 & 3.3 & 4.2 & 4.6 \\
\hline 23 & 2 & OR & 3.2 & 3.9 & 1.2 & 1.9 & 4.8 & 8.7 & 1.2 & 3.8 & 5.8 & 12.7 & 5.2 & 6.7 & 6.4 & 2.9 & 9.0 \\
\hline 23 & 3 & OR & 5.5 & 5.6 & 2.9 & 1.4 & 9.6 & 11.8 & 2.5 & 3.3 & 7.7 & 10.8 & 8.3 & 7.5 & 4.9 & 3.6 & 10.9 \\
\hline 24 & 1 & PD & 8.5 & 6.3 & -0.3 & -0.3 & 5.9 & 10.5 & -0.5 & 28.6 & 3.2 & 10.1 & 2.2 & 3.9 & 4.1 & 1.9 & 3.8 \\
\hline 24 & 2 & PD & 3.0 & 3.8 & -0.5 & -1.4 & 7.9 & 9.5 & 3.2 & 2.0 & 4.6 & 12.7 & 2.8 & 3.5 & 2.7 & 6.3 & 8.4 \\
\hline
\end{tabular}




\begin{tabular}{|c|c|c|c|c|c|c|c|c|c|c|c|c|c|c|c|c|c|}
\hline 24 & 3 & PD & 8.1 & 9.5 & -1.3 & 0.5 & 13.0 & 14.3 & 8.9 & 3.4 & 9.8 & 8.9 & 13.3 & 5.8 & 6.0 & 7.4 & 14.3 \\
\hline 25 & 1 & PN & 4.9 & 5.3 & 4.2 & 4.1 & 8.9 & 8.8 & 9.0 & 3.4 & 5.3 & 9.0 & 8.2 & 5.4 & 4.2 & 1.1 & 6.3 \\
\hline 25 & 2 & PN & 4.5 & 5.1 & 4.7 & 4.9 & 8.6 & 9.1 & 7.9 & -0.3 & 3.7 & 10.6 & 2.9 & 2.4 & 7.8 & 3.4 & 6.3 \\
\hline 25 & 3 & PN & 4.6 & 4.7 & 2.1 & 2.0 & 5.4 & 5.9 & 5.5 & 9.4 & 5.5 & 10.5 & 5.0 & 3.6 & 5.5 & 0.7 & 13.4 \\
\hline 26 & 1 & RJ & 3.5 & 3.8 & 2.6 & 2.8 & 3.4 & 4.7 & 2.5 & 4.2 & 4.6 & 11.3 & 3.7 & 4.2 & 8.9 & 4.1 & 5.2 \\
\hline 26 & 2 & RJ & 6.2 & 6.1 & 5.3 & 4.5 & 5.5 & 8.5 & 2.4 & 7.7 & 7.0 & 11.6 & 9.3 & 8.3 & 7.2 & 3.4 & 5.4 \\
\hline 26 & 3 & RJ & 5.4 & 5.4 & 3.1 & 2.4 & 5.7 & 5.7 & 5.9 & 7.6 & 6.3 & 10.9 & 5.3 & 6.2 & 6.4 & 4.0 & 11.4 \\
\hline 27 & 1 & SK & . & . & . & . & . & . & . & . & . & 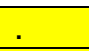 & . & . & . & . & . \\
\hline 27 & 2 & SK & 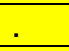 & & & & & & & & & & 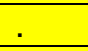 & 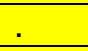 &. &. & \\
\hline 27 & 3 & SK & 6.9 & 6.8 & 2.4 & 2.6 & 4.2 & 4.7 & 3.7 & 10.7 & 7.3 & 17.3 & 2.5 & 8.4 & 8.9 & 4.0 & 11.6 \\
\hline 28 & 1 & TN & 2.8 & 3.2 & 1.6 & 1.6 & 5.2 & 7.7 & 0.7 & 2.9 & 3.1 & 6.7 & 2.7 & 1.7 & 8.5 & 4.1 & 4.0 \\
\hline 28 & 2 & $\mathrm{TN}$ & 4.2 & 4.6 & 3.4 & 3.3 & 2.8 & 5.3 & -1.2 & 4.9 & 5.4 & 10.6 & 4.9 & 3.1 & 8.5 & 6.4 & 5.3 \\
\hline 28 & 3 & $\mathrm{TN}$ & 5.5 & 6.2 & 1.3 & 1.2 & 4.3 & 4.4 & 4.3 & 0.5 & 8.1 & 10.4 & 8.2 & 6.1 & 6.2 & 9.2 & 9.5 \\
\hline 29 & 1 & TR & 3.9 & 5.0 & 3.9 & 4.7 & 7.0 & 10.4 & 6.3 & 5.0 & 3.4 & 8.8 & 3.1 & 3.4 & 13.1 & 0.7 & 12.6 \\
\hline 29 & 2 & TR & 4.0 & 5.3 & 1.1 & 3.5 & 1.9 & 10.2 & -2.0 & 5.0 & 6.9 & 15.9 & 5.4 & 13.1 & 10.6 & -2.8 & 10.8 \\
\hline 29 & 3 & TR & 6.9 & 7.9 & 4.8 & 4.8 & 2.2 & 3.0 & 4.2 & 16.8 & 7.6 & 1. & 4.6 & 8.2 & 7.5 & 12.6 & 11.5 \\
\hline 30 & 1 & UP & 2.6 & 2.6 & 2.0 & 1.9 & 4.2 & 5.1 & 3.4 & 4.5 & 2.8 & 7.0 & 2.7 & 3.2 & 2.4 & 1.8 & 4.1 \\
\hline 30 & 2 & UP & 4.7 & 5.2 & 3.0 & 4.0 & 9.1 & 11.9 & 5.6 & 1.3 & 5.5 & 13.7 & 4.4 & 6.9 & 8.0 & 4.2 & 5.1 \\
\hline 30 & 3 & UP & 4.1 & 4.2 & 2.6 & 1.9 & 2.9 & 1.6 & 4.5 & 9.1 & 4.9 & 10.1 & 3.2 & 4.6 & 6.3 & 2.6 & 8.5 \\
\hline 31 & 1 & UT & . & . & . & . & . & 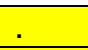 & . & . & . & 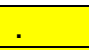 & . & . & . & . & \\
\hline 31 & 2 & UT &. & - &. &. & . & . & . & . &. & . &. &. &. & . & . \\
\hline 31 & 3 & UT & 7.2 & 7.5 & 1.9 & 1.8 & 9.0 & 11.5 & 5.8 & 12.7 & 7.8 & 10.6 & 8.4 & 6.2 & 9.6 & 2.9 & 10.3 \\
\hline 32 & 1 & WB & 3.2 & 3.4 & 2.3 & 3.4 & 2.4 & 2.3 & 2.7 & 5.6 & 4.1 & 4.8 & 2.7 & 5.6 & 3.1 & 4.4 & 4.6 \\
\hline 32 & 2 & WB & 4.3 & 4.7 & 3.9 & 5.7 & 2.8 & 2.3 & 3.5 & 4.3 & 4.8 & 6.5 & 5.1 & 3.2 & 6.7 & 2.6 & 7.2 \\
\hline 32 & 3 & WB & 6.0 & 6.2 & 2.7 & 2.6 & 6.4 & 4.8 & 7.7 & 7.7 & 7.5 & 1. & 7.0 & 5.9 & 6.0 & 9.6 & 8.5 \\
\hline
\end{tabular}

Y_1:NSDP at Factor Cost; 2004-05 prices as estimated by adding up sübcomponents

Y: NSDP at Factor Cost chained backwards

$P$ 1: In Primary Sector addition of subcomponents

PA : Primary - Agriculture

SM: Secondary - Manufacturing

SMR: Secondary - Reg. Manufacturing

SMU: Secondary - Unreg. Manufacturing

SC: Secondary - Construction

Figures are growth rates per annum over the period

T_1: Tertiary Sector as estimated by adding up all sub sector estimates

TB ; Tertiary - Banking, Insurance etc

TH: Tertiary - Trade, Hotels and Restaurants

TC: Tertiary - Other services

TP: Tertiary - Public Services

TR: Tertiary - Real Estate, Dwellings etc

TT: Tertiary - Transport, Storage and Communication

Per.: 1961/1971 to 1979

Per. 2: 1980 to 1992

Per.3: 1993 onwards to 2010 